NBER WORKING PAPER SERIES

\title{
THE EFFECT OF STATE WORKERS' COMPENSATION PROGRAM CHANGES ON THE USE OF FEDERAL SOCIAL SECURITY DISABILITY INSURANCE
}

\author{
Melissa P. McInerney \\ Kosali I. Simon \\ Working Paper 15895 \\ http://www.nber.org/papers/w15895
NATIONAL BUREAU OF ECONOMIC RESEARCH
1050 Massachusetts Avenue
Cambridge, MA 02138
April 2010

Corresponding author acknowledges support from the National Institute on Disability and Rehabilitation Research (NIDRR) through the Cornell University NIDRR Employment Policy RRTC. We thank Richard Burkhauser, John Burton, Xuguang Guo, Andrew Houtenville, and David Stapleton for sharing data that made this project possible. We are grateful to Richard Burkhauser, Susanne Bruyere, John Burton, Mark Duggan, Xuguang Guo, Judith Hellerstein, Andrew Houtenville, and David Stapleton for advice and encouragement. We thank Anna Choi, James Hunsberger, and Aparna Lhila for outstanding research assistance. The views expressed herein are those of the authors and do not necessarily reflect the views of the National Bureau of Economic Research.

NBER working papers are circulated for discussion and comment purposes. They have not been peerreviewed or been subject to the review by the NBER Board of Directors that accompanies official NBER publications.

(C) 2010 by Melissa P. McInerney and Kosali I. Simon. All rights reserved. Short sections of text, not to exceed two paragraphs, may be quoted without explicit permission provided that full credit, including (c) notice, is given to the source. 
The Effect of State Workers' Compensation Program Changes on the Use of Federal Social Security Disability Insurance Melissa P. McInerney and Kosali I. Simon

NBER Working Paper No. 15895

April 2010

JEL No. I1,I28,J28,J78

\section{ABSTRACT}

In addition to traditional forms of private and public medical insurance, two other large programs help pay for costs associated with ill health. In 2007, Workers Compensation (WC) insurance provided $\$ 55.4$ billion in medical care and cash benefits to employees who are injured at work or contract a work-related illness, and Social Security Disability Insurance (DI) provided \$99 billion to individuals who suffer from permanent disabilities and are unable to engage in substantial gainful activity. During the 1990s, real DI outlays increased nearly 70 percent, whereas real WC cash benefit spending fell by 12 percent. There has been concern that part of this relationship between two of the nation's largest social insurance programs may be due to individuals substituting towards DI as state WC policies tightened. We test this hypothesis using a number of different WC and DI program parameters. We first show that this negative correlation between the national series does not hold over time within states, the level at which a causal relationship should operate. We then test how regulatory changes in state WC program parameters impact WC outcomes (intended effect) and DI outcomes (unintended effect). We find no compelling evidence of WC tightening causing DI rolls to increase, and conclude it is unlikely that state WC changes were a meaningful factor in explaining the rise in DI.

Melissa P. McInerney

Assistant Professor, Department of Economics, College of William and Mary,

P.O. Box 8795

Williamsburg, VA 23187

mpmcinerney@wm.edu

Kosali I. Simon

Associate Professor

Department of Policy Analysis and Management

Cornell University

103 MVR Hall

Ithaca, NY 14850

and NBER

kis6@cornell.edu 


\section{Introduction}

In addition to traditional forms of private and public medical insurance, two other large government programs help pay for costs associated with ill health. In 2007, Workers Compensation (WC) insurance provided $\$ 55.4$ billion in medical care and cash benefits to employees who are injured at work or contract a work-related illness, and Social Security Disability Insurance (DI) provided $\$ 99$ billion to individuals who suffer from permanent disabilities and are unable to engage in substantial gainful activity. During the 1990s, the employment of working aged people with disabilities fell dramatically (e.g., Stapleton and Burkhauser (2003)), while total annual spending on Social Security Disability Insurance (DI) and the number of individuals receiving DI rose. There have been many factors found to be partially responsible for explaining these trends. For example, Duggan and Imberman (forthcoming) attribute much of the rise in the DI rolls to the characteristics of the individuals insured by the DI program, the state of the economy, and the generosity of program benefits, while other researchers have considered the effect of federal policy changes such as the Americans with Disabilities Act of 1990 in explaining changes in employment rates among the disabled community (e.g., DeLeire (2000); Acemoglu and Angrist (2001); Houtenville and Burkhauser, (2004)). However, there is also a substantial amount of this trend left to explain. As policymakers seek to better integrate working age people with disabilities into the workforce, it is important to understand the factors leading to this rise in DI spending and the concurrent fall in employment rates among individuals with disabilities. This is an important policy question because while employment for working aged people disabilities was falling, the poverty rate for adults with disabilities also deteriorated relative to their non-disabled peers (Burkhauser et al. (2005b)). There may also be an unexplored role played by state policies to explain changes in the DI program and related outcomes. In this paper, we consider the impact that one specific set of state policies, those concerning Workers' Compensation (WC), the program that compensates workers who become injured on the job, may have on WC outcomes, and on disability applications, and thus potentially on employment decisions among working aged disabled individuals. 
Total real dollars spent on WC fell 12\% during the 1990s. This occurred during a time period when many states enacted reforms to make WC more difficult for workers to claim. This has lead to the question of whether there is any substitution between the two programs that may help explain this observed trend, above and beyond the factors researchers already have found account for some of this trend-i.e., do individuals who are at the margin and potentially eligible for both programs substitute towards DI when WC rules tighten. Although this has been hypothesized in the literature (see, e.g., Thomason et al. (2001), Burton and Speiler (2001), Sengupta et al. (2009)), there has been no empirical testing of this conjecture other than contemporaneous work by Guo and Burton (under review), an earlier version of which is in LERA proceedings (Guo and Burton (2008)).

The expected impact of WC policy changes on the employment of individuals with disabilities is ambiguous. Consider a broad definition of disability that includes anyone who suffers a workplace injury who would have received any WC. This group is comprised of those whose injuries are severe enough to be eligible for federal disability benefits and those whose injuries are not severe enough to meet the threshold set by the federal program. For the severely injured workers, a restriction of WC may lead to a decline in the employment rate for those persons with disabilities if they earlier received WC but now would move onto DI. ${ }^{1}$ For the less severely injured workers, any decline in receipt of WC that is not made up for by an increase in receipt of DI may cause the individual to return to work sooner - that is, being without either program causes a stronger attachment to the labor force than being on WC by itself. Thus, the theoretical effect of WC policy changes on the employment of people with disabilities is ambiguous. ${ }^{2}$

In order for state WC programs to have an effect on DI applications and the employment status of

\footnotetext{
${ }^{1}$ DI programs are generally available only to those not employed, whereas in many states, once permanent partial WC benefits are awarded, injured workers may return to work while receiving benefits. For example, in California permanent partial disability benefits are awarded based on an injured worker's previous earnings and a doctor's determination of the extent of permanent disability (adjusted for the worker's age and occupation). Permanent partial disability benefits are not reduced if the injured worker is employed while receiving such benefits. California Division of Workers' Compensation (2009).

${ }^{2}$ In this paper, we employ the broad definition of disability. Under a restricted definition of disability that only includes workers who would be eligible for DI were they to apply, tightening WC benefits is predicted to unambiguously reduce the employment of people with disabilities.
} 
people with disabilities, it must be the case that for a certain population, both WC and DI are available options. Workers whose ability to perform basic duties of employment is compromised due to health can avail themselves of the federal DI system for conditions that are expected to last 12 months or more. The state WC system is available to compensate injuries that are caused by work, regardless of the expected length of condition. A worker may receive services from both programs concurrently (subject to offsets discussed later), and it is also possible that a worker would first qualify for WC services and then transition to DI thus receiving benefits from only one program at any given time. ${ }^{3}$ Injured workers suffering more serious workplace injuries receive permanent WC benefits, and a substantial number of WC claimants receiving permanent WC benefits are also receiving DI. ${ }^{4}$ In fact, as of December 2008, 15.5 percent of DI beneficiaries had some connection to WC or other public disability benefits (Sengupta et al., 2009, Table 16). Thus, not all workers who qualify for WC would qualify for DI (e.g., those whose conditions are less severe/receive temporary benefits), nor do all DI recipients qualify for WC (e.g., those whose disability is not caused by work). But as long as there exists an intersection between these two sets (those whose injuries are considered work related and are severe enough to last up to a year), a tightening of WC rules may cause a worker to: (1) file for WC and DI simultaneously, (2) file for DI instead of WC, or (3) file for WC initially and then transition to DI, either while maintaining WC or by exiting WC. ${ }^{5} \mathrm{WC}$ policy changes create incentives for workers to change their behavior in (1)-(3) above, but other players (employers, insurers, and the state) also stand to gain from workers substituting towards DI.

Of course, one assumption inherent in this study of whether WC tightening leads to DI program growth is that there are no concurrent changes in DI program generosity that explain the trend. If DI

\footnotetext{
${ }^{3}$ DI applications are lengthy whereas WC benefits start almost immediately upon determination. Thus, workers who expect they will receive DI for an injury might start out applying for WC. About one quarter of DI claims are won on appeal or reconsideration, thus making receiving $\mathrm{WC}$ in the interim an attractive option. (Social Security Administration, 2008, Chart 11).

${ }^{4}$ There are also legislative reasons why the two programs may be positively correlated. For example, Oregon Revised Statute 656.209 requires than anyone receiving WC for permanent total benefits also file an application for DI so that WC costs could be offset by DI payments.

${ }^{5}$ It is unclear a priori which of these reactions is likely to be more plausible. In our current tests, we consider both the possibility of diversion away from WC (which is reflected in the frequency of WC receipt) as well as the possibility of receiving WC benefits for a shorter time (which is partially reflected in the transition to permanent benefits and total WC benefit dollars).
} 
became more generous, the observed trend may simply reflect the fact that individuals eligible for both programs may choose the more generous of the two, leading to a growth in total DI spending and a fall in total WC spending. Autor and Duggan (2003) document an increase in the DI earnings replacement rate during the 1980s and 1990s. Changes in DI generosity impacted all workers in the U.S. whereas changes in WC occurred at the state level. We exploit state-by-year level changes in WC generosity to isolate the role of WC changes in any shifting away from WC to DI, above and beyond increased DI generosity.

In this paper, we first describe the two programs to consider the scope for a causal effect of WC reforms on DI applications. Next, we describe the prior literature relevant to this question, and proceed to lay out our empirical tests and data. We present national descriptive time trends in DI and WC program statistics, as well as estimates from regressions using state by year data where we first study whether WC and DI are negatively correlated at the state level, and then study the causal effect of WC reforms on the possible substitution of DI for WC. We conduct our analysis using multiple measures of WC outcomes, DI outcomes and WC program parameters. Data on DI applications and new cases were generously provided by Richard Burkhauser, Andrew Houtenville, and David Stapleton, and we thank John Burton and Steve Guo for sharing data on severe WC cases. The remaining data series are publicly available from different government or non government agencies but many of which have been hand entered from historical sources and have not been used in DI or WC research in the past.

We find that the negative correlation between measures of DI and WC receipt which appears in the aggregate national statistics is not upheld at the state level, casting doubt on whether a causal link exists. In our regressions that examine the impact of variation in WC program generosity on WC and DI program receipt and benefit spending at the state by year level, we generally find no evidence of a statistically significant relationship. We do find some coefficients that are statistically significant, but this is not surprising given the large number of parameters we estimate; we cannot rule out that the few statistically significant relationships we do find arise simply due to chance. Our overall conclusion based on all available state level data is that it is unlikely that WC policy changes have contributed to the rise of 
DI applications, cases, and benefits and to the decline in employment among individuals with disabilities.

Although it is possible that a causal relationship between the two programs exists that we cannot detect with our data (i.e., that at the individual level, there could be cases where WC tightening lead to DI applications), we argue that our approach answers the question that motivated this paper: that the decline in WC outcomes during the 1990s is not a significant factor in the increase in DI outcomes during the same period. Even if individuals at the margin are increasingly claiming DI more than WC, if these changes are too small to detect in our state by year level data, then behavior by individuals at the margin is unlikely to be driving the aggregate trends that prompted the initial concern about WC tightening leading to DI growth.

\section{Background}

\section{Workers' Compensation Benefits}

WC insurance provides medical care and cash benefits to employees who are injured at work or contract a work-related illness. ${ }^{6} \mathrm{WC}$ is administered at the state level, and all states (except Texas) mandate that employers provide WC insurance. Employers may purchase private insurance, public insurance, or self-insure their risks (not all options are available in every state), but benefits to all injured workers in a state must follow the state mandated benefit provisions. ${ }^{7}$ Workers injured on the job receive medical care immediately but must be away from work between three and seven days before receiving cash benefits to replace lost wages. ${ }^{8} \mathrm{WC}$ is one of the largest social insurance programs in the United States. In 2007, individuals received a total of $\$ 55.4$ billion in cash and medical payments for WC $-\$ 28.2$ billion in cash benefits and $\$ 27.2$ billion in medical care (Sengupta et al., 2009). Spending on cash benefits for WC during the 1990s and early into the present decade exceeded federal spending on

\footnotetext{
${ }^{6}$ Most WC laws require that the injury or occupational disease must be a direct result of a workplace activity (the exact language varies from state to state), although this has been sometimes hard to prove. Thus, there is debate over what happens if the injury occurs during a company softball game, while driving to work, in the parking lot, in the cafeteria, etc. Fault is generally immaterial, although recent cases have brought up issues such as what happens when the employee is drunk or disregarded employer instructions and engaged in dangerous activities.

${ }^{7}$ Approximately half of all benefits are paid through private insurance, one quarter through self-insurance, and one quarter through state funds and federal programs (Sengupta et al., 2009).

${ }^{8}$ This waiting period varies across states.
} 
Unemployment Insurance, Food Stamps, and Temporary Assistance for Needy Families (Green Book, 2004). The injured workers' weekly benefits are a function of their weekly earnings, and generally replace two-thirds of pre-injury weekly earnings, subject to a maximum which varies across states. ${ }^{9}$ In 2004 , the latest year for which we have data, the state maximum ranged from $\$ 341$ per week in Mississippi to $\$ 1,133$ per week in Iowa. ${ }^{10}$

Typically, injured workers receiving cash benefits first receive Temporary Total Disability (TTD) benefits. Injured workers receive these benefits until one of three things happen: (1) they are able to return to work, at which point they are no longer considered totally disabled and cash benefits cease; (2) the physician has determined that the injured worker has reached "Maximum Medical Improvement" and the injured worker is evaluated for permanent disability benefits; or (3) the injured worker has reached the state time limit for temporary benefits and is evaluated for permanent disability benefits.

There are two types of permanent disability benefits in WC-Permanent Partial Disability (PPD) benefits and Permanent Total Disability (PTD) benefits. The most common is PPD benefits, comprising 66 percent of all WC cash benefits in 2004. ${ }^{11}$ If any injured workers are substituting DI for WC due to a policy change in WC, it is likely to be workers potentially eligible for PPD who are driving the aggregate trends in DI outcomes and the employment of working aged people with disabilities. Those on PTD constitute less than 1 percent of all WC cases, and would have been more likely to be on DI — and unable to work - regardless of the tightening of WC policies as the nature and duration of their injuries are so severe. Furthermore, only PPD recipients are free of disincentives to work, as described below.

PTD benefits are provided in much the same way as TTD benefits and have the same disincentives to work. Injured workers receive a benefit equal to two-thirds of their pre-injury weekly earnings, subject to a maximum that varies across states. Benefits cease when the worker has healed,

\footnotetext{
${ }^{9}$ The state-mandated benefit schedule also applies to injured workers whose employers choose to self-insure their WC risks.

${ }^{10}$ The median state's maximum was $\$ 596$ per week in 2004 (U.S. Chamber of Commerce, 2004).

${ }^{11}$ In 2004, TTD benefits comprised 17 percent of WC cash benefits and PTD and fatalities comprised 17 percent of WC cash benefits. (Sengupta, et al., 2009)
} 
returns to work (and is obviously neither permanently nor totally disabled), or reaches the state maximum number of weeks for PTD benefit receipt.

There are two main ways PPD benefits are provided, and in general, recipients of PPD benefits face no disincentives to work. First, some injuries (such as the loss of an arm or a thumb) are compensated based on a fixed schedule that dictates the number of weeks an injured worker may receive benefits. ${ }^{12}$ As with temporary and PTD claims, the weekly benefit is generally two-thirds of a worker's pre-injury weekly earnings subject to a maximum that varies by state. For example, in Ohio, injured workers who lose a thumb will receive benefits for 60 weeks. ${ }^{13}$ In contrast to DI benefits, which are reduced or cease when an individual returns to work, for scheduled PPD benefits, everyone who loses a thumb is eligible to receive these benefits for 60 weeks. Thus, individuals may return to work without compromising their PPD benefits. ${ }^{14}$ PPD claims for injuries that are not on the state's schedule, "unscheduled injuries," tend to be provided as an increasing function of the fraction of the body injured. For injuries such as persistent lower back pain, states generally use the American Medical Association's rating guide to determine the percentage of the body that is impaired, and the worker receives a benefit corresponding to the percentage amount. This benefit tends to be delivered either as a lump sum or the injured worker will receive benefits for a fixed number of weeks (Barth (2005)). When benefits are delivered as a lump sum, the injured worker receives a one-time payment while agreeing to waive the right to receive further cash or medical benefits for the claim (Barth (2005)). In 19 states, unscheduled PPD benefits are based only on the degree of impairment, and not related to the loss of earnings in the workplace (Barth (2005)). Therefore, many PPD recipients face no disincentives to work (i.e., injured workers receiving scheduled benefits, those awarded lump sum benefits, or workers who reside in those 19 states in which unscheduled PPD benefits are based only on impairment).

\footnotetext{
${ }^{12}$ An injured worker's weekly benefit is a function of the worker's pre-injury earnings. In general, the weekly benefit is computed from the same schedule whether the benefit is classified as temporary total disability, PPD, or PTD.

${ }^{13}$ Ohio Revised Code $\$ 4123.57$.

${ }^{14}$ Some injuries, such as the loss of two legs or two arms, automatically qualify for PTD benefits in much the same way as scheduled PPD injuries. Individuals suffering such injuries are also free of disincentives to work.
} 


\subsection{Social Security Disability Insurance}

DI is a federal program administered by the Social Security Administration. In 2007, DI paid \$99 billion to 7.1 million disabled workers and their families. To even be considered for DI, injured workers must have worked in Social Security covered employment. ${ }^{15}$ To receive DI benefits, disabled workers must show that they have a disability which is expected to last at least 12 months and that they are unable to do the jobs they most recently left or engage in any "substantial gainful activity" available in the economy. Neither medical nor cash benefits are available at the time of the disabling event. ${ }^{16}$ At least five months must pass between the disabling event and the time period for which the first benefit check is received, and there is a mandatory 29-month waiting period between the disabling event and the onset of Medicare benefits. Furthermore, the application process can be long and costly; it can take between three and five months for a decision to be made. Since one of the eligibility criteria is that the individual cannot work, this means that applicants must not engage in "substantial gainful employment" for the disability determination period. ${ }^{17}$ State boards make the initial disability determination, and rejected applicants can appeal the decision. According to the Social Security Advisory Board, of those applying for DI in 2000, only 40 percent of applicants were awarded DI at the state board level. This means that sixty percent of applicants either appealed the decision or were never awarded DI benefits. Thus, many applicants face an initial rejection, and those choosing to appeal this decision must remain out of work, without DI benefits, for well over five months. ${ }^{18}$

If awarded DI, the worker receives benefits that are rather generous. Benefits are progressive,

\footnotetext{
15 The required number of quarters worked increases with age.

${ }^{16}$ Many papers examine both firm and worker level factors that predict whether workers with disabilities are able to adapt and remain employed (e.g. Schur et al 2009, Campioleti 2004, Burkhauser et al 1999, Daly and Bound 1996, Burkhauser et al 1995).

17 "Substantial" employment is defined as earning more than $\$ 980$ a month pre-tax in 2009 . While an application is being considered, the person may be working (and even after it has been approved) as long as the work does not exceed $\$ 700$ per month. This amounts to less than 2.5 hours of work a day at around $\$ 15 / \mathrm{hr}$. If the person earns more than that, they will be denied on technical grounds. Social Security Administration (2009).

${ }^{18}$ In fact, disabled individuals appealing an initial decision often remain out of work much longer than the requisite five months. There is a 24 month waiting period before Medicare coverage begins for DI recipients, and Livermore et al. (2009) find that the average DI recipient is already nine months into the 24 month Medicare waiting period when awarded benefits.
} 
computed in the same way as Social Security retirement benefits. ${ }^{19}$ Recipients receive the full award for their life, and the average after-tax replacement rate is approximately 60 percent (Bound and Burkhauser (1999)) ${ }^{20}$ After a two-year waiting period, recipients are eligible to receive Medicare coverage. There are work incentives to encourage recipients to return to work, but those policies are fairly recent. Once someone has recovered and worked for an extended period, DI benefits generally cease.

\subsection{Relationship between Workers’ Compensation and Social Security Disability Insurance}

The potential for there to be consequences for the DI program from WC state programs tightening has been suggested by researchers familiar with the two programs, but the empirical economics literature has just begun to investigate the relationship. In 2004, the National Academy of Social Insurance (NASI) held a conference on the relationship between these two programs. ${ }^{21}$ In some of the earliest discussions of this phenomenon, Mont et al. (2000) and Thomason et al. (2001) point to growth rate of WC benefits falling dramatically at the national level between 1992 and 1998. They show that after many years of double-digit growth rates, the annual percentage increases in $\mathrm{WC}$ costs for medical and cash benefits grew (or contracted) by minuscule amounts between 1992 and 1998, the latest year of their data. During this same period, national DI benefit spending increased by 33 percent. The possibility of a link between the two programs has also been suggested in the annual publication, "Workers' Compensation Benefits, Coverage, and Costs," published by the National Academy of Social Insurance. This publication presents the two national series, DI benefits per $\$ 100$ of "covered wages" (or the earnings of those insured under WC) and WC benefits per $\$ 100$ of covered wages for the years 1980 to 2007 . Between 1980 and 1990 , WC benefits per $\$ 100$ in covered wages were rising while DI benefits per $\$ 100$ in covered wages were falling. These trends reversed from 1990 onward, suggesting a negative relationship between the two

\footnotetext{
${ }^{19}$ The proportion of covered wages replaced by Social Security benefits declines as covered wages increase.

${ }^{20}$ Individuals awarded DI benefits receive DI benefits until they reach full retirement age, at which point the benefit becomes an Old Age benefit from the Social Security Administration. However, the payments do not change, so the individual essentially receives benefits for life. "511. When does your period of disability end?" Social Security Handbook, http://www.ssa.gov/OP_Home/handbook.05/handbook-toc05.html. (last viewed January 21, 2010)

${ }^{21}$ Proceedings from this conference were published in the Social Security Bulletin, 65(4), released May 2005. In it, James B. Lockhart, III, Deputy Commissioner of Social Security, stressed how important the relationship between the two programs is to his agency. He noted that the Social Security Administration devotes over 1,000 full time equivalent employees to handling the offset between the two programs (Lockhart (2005)).
} 
programs when benefits are measured relative to covered wages.

One relevant question is the extent to which workers are potentially eligible for either program. One might document how many of those receiving permanent WC benefits are also potentially eligible for DI. There is no data we know of that would allow us to construct this measure. ${ }^{22}$ Conversely, one might also document the extent to which the injuries of DI recipients are work related. Schoeni and Reville (2006) use the 1992 Health and Retirement Survey that is reflective of those 51 to 61 years of age, and show that among those receiving DI, 37 percent became disabled due to a work-related injury. They also show that the fraction on DI due to a workplace injury differs by type of disability, with high fractions in musculoskeletal causes. Similarly, Sengupta et al. (2009) find that in 2008 approximately 15.5 percent of DI beneficiaries had some connection to WC or other public disability benefits. Woock (2009) shows that among workers injured on the job, long term earnings losses are limited to those whose injuries resulted in disabilities.

Policy makers have recognized from the start of the DI program that a certain group of workers could be eligible for both programs. Starting in 1965, a Social Security Amendment specified that workers who receive DI benefits will see reductions in the DI payments when they receive WC payments so that the combined value of DI and WC payments cannot exceed 80 percent of a worker's average preinjury earnings. In 15 states, there is a reverse offset and WC payments, not DI payments, are reduced. In states with the reverse offset, employers and insurers (and the state) have a clear incentive to see that more of the WC cases are on DI concurrently; in all states there is an incentive to see fewer workers on WC and more on DI to keep employer WC costs low and a state attractive to business.

From the injured worker's perspective, WC and DI benefits complement one another, and injured

\footnotetext{
${ }^{22}$ Roberts (1994) obtained data from the Michigan Bureau of Workers' Disability Compensation for claims occurring in 1984 and 1985. Beginning in 1981, WC benefits were coordinated with other types of employer-paid benefits. Employers were required to report the types of additional benefits injured workers received. Even this dataset does not contain information about SSDI receipt because at the time of this study, WC benefits were not reduced by SSDI benefits in Michigan. (Approximately one percent of WC recipients concurrently received some other employer-provided long-term disability benefit.)
} 
workers may have an incentive to claim DI even in the absence of WC program changes. This is true even though the offset rules limit the combined value of DI and WC payments to 80 percent of a worker's preinjury earnings. WC cash and medical benefits are available immediately after the workplace injury in contrast to DI cash benefits (and Medicare) which are subject to lengthy waiting periods. WC benefits are not taxed, so after-tax replacement rates can be close to one for WC (Meyer, 2002). However, DI benefits are taxed and have after-tax replacement rates of approximately 60 percent. While many $\mathrm{WC}$ benefits are time limited, DI benefits are not time-limited, which is especially attractive to WC PPD beneficiaries who often receive benefits for a fixed number of weeks. Furthermore, DI benefits are adjusted over time to reflect changes in the cost of living whereas most state WC benefits are not adjusted in a similar way. DI also has a third advantage over WC; when Medicare coverage begins for DI beneficiaries, it provides health coverage for all conditions, not only for the workplace injury. ${ }^{23}$ In fact, qualitative evidence from surveys of health workers suggests that fear of losing benefits, such as health insurance, is one of the reasons injured workers choose not to apply for WC benefits (Galizzi et al., (2010)). In this paper, we examine how WC program changes impact the incentive for injured workers to claim DI benefits above and beyond concurrent claiming that may arise because the two programs complement one another. In the next section, we examine the motives to workers, employers, and states to shift injured workers from WC to DI.

\section{Hypothesis}

Clearly, state WC program costs would be higher if the federal DI program did not exist, to the extent that injuries of those on DI had a work related component. It is also clear from this discussion that DI costs would be higher if WC did not exist as those with severe work related injuries would qualify for DI. WC and DI are intertwined in purposes and populations covered. For those who are injured at work and face a possible permanent disability, both options maybe available. It could be the case that those who would qualify for both programs always choose the more generous of the two. Autor and Duggan (2003)

\footnotetext{
${ }^{23}$ Individuals who receive a lump sum WC benefit also have every incentive to pursue DI benefits.
} 
document a rising earnings replacement rate over this time period for DI recipients. Therefore, to rule out the possibility that DI receipt increased because that program become more generous, we examine responses to changes in WC generosity that occurred at the state level. DI and WC claiming series could also move together to reflect changing health status within a population-for example, an aging workforce is likely to experience more disabilities — both work related and non work related. A changing industrial mix or other changes in workplace safety features are other reasons the two series may move together. However, the tightening of WC generosity could cause those whose workplace injuries are expected to last a year or more to apply for DI instead of WC or to apply for DI while receiving WC when they otherwise would not. ${ }^{24}$ If any state WC policies shift workers from the WC rolls to the DI rolls, this should be reflected in a decrease in permanent WC receipt rather than other forms of WC.

In our simple conceptual framework, the most directly involved player in explaining the connection between WC changes and its effect on DI is the worker, but the employers, insurers and the state also play a potential role. Workers are likely to react to changes in the net expected benefits of applying for WC versus DI, but it is important to note that employers, insurers, and the state all have incentives to shift workers from WC to DI, especially in times of rising WC costs, such as the early 1990s (Sengupta et al., (2009).

- Workers: When WC net benefits decline due to reduced benefits; increased costs of applying; lower quality of medical care due to restrictions in choice of the treating physician; or lower probability of receiving benefits, then DI will become a more attractive option (assuming no concurrent change that happens in DI net generosity at the federal level) for workers whose injuries are such that both programs are options. We focus on changes to net benefits that occur due to state level policy changes, rather than from other sources that may be potentially spurious such as state changes in workplace safety, which might increase the fraction of workers whose

\footnotetext{
${ }^{24}$ It may also be the case that someone whose injuries are severe but are not entirely caused by work was able to receive $\mathrm{WC}$ before state policies tightened, and now cannot.
} 
injury would qualify for DI as well as WC. When WC becomes less generous, some workers may forgo WC entirely, while others may apply for DI as an additional benefit to WC.

- Employers: It is in the interest of employers to have workers apply for DI instead of WC when WC costs are growing for those employers who are self-insured or experience rated in any way (i.e., having more workers on WC implies higher costs passed through to the employers). Thus, employers could play a role in making WC harder to obtain or in assisting the workers to apply for DI instead, especially in cases where employers self- insure benefits (and thus face perfectly experience rated premiums). ${ }^{25}$

- Insurers: If WC cases can be shifted to DI, insurer costs will fall. Insurers benefit from being able to reduce their costs and offer lower premiums in a competitive insurance market (or one in which they are the state monopoly) and thus also have incentives to have workers move from WC to DI when WC costs increase.

- State: States have incentives to shift workers from WC to DI because WC is financed by the state's employers. In contrast, DI is financed at the federal level. Often, the state also faces the incentives that are relevant to insurers described above when the state provides $\mathrm{WC}$ insurance through its operation of a state insurance fund.

Thus, workers who are on the margin of DI and WC face incentives to move to DI (as a substitute or in addition to WC) when WC appears less attractive an option. Around them are other players (employers, insurers and the state) who also stand to gain from such moves, and may act in ways that facilitate this change in worker claiming behavior. In summary, our hypothesis is that as there are reductions to a worker's expected benefits of applying for WC, the worker is more likely apply for DI. This theory applies only to workers who are at the margin. To the extent that there are enough such workers to affect the aggregate statistics (and the phenomenon is a reason for the declining WC and DI time series being

\footnotetext{
${ }^{25}$ Under the offset rules, the default is to reduce the DI dollars. However, in reverse offset states, WC dollars are reduced, providing an added incentive for employers, insurers and the state to see injured workers obtain DI in those cases.
} 
causally related), the causal relationship should be observable in state level data. While there may be a relationship that could only be observed at the individual worker level (but is not feasible to test with existing datasets to the best of our knowledge), the state level trends are relevant for policy implications. ${ }^{26}$

The motivation behind our hypothesis is similar to that used in Autor and Duggan (2003), who document the decline in unemployment in the 1990s and the concurrent increase in the receipt of DI. They argue that as DI became relatively more generous over time, the number of workers who are “conditional applicants" increased and more of them applied for DI. They classify potential DI applicants into three groups: always apply, never apply, and apply if unemployed (the conditional applicants). The group of conditional applicants will grow if the probability a DI claim is accepted grows or the benefit grows. Our hypothesis is quite similar. If the cost of applying to DI remained the same for these injured workers, but the generosity of WC decreased because of WC reform, then more workers will apply for DI, and fewer workers apply for WC (although those who apply for DI might continue to apply for WC as well if they are the more severely injured workers who will not be denied WC due to WC reforms). We expect that the introduction of WC reforms that reduce payment levels or the probability of an award would increase the number of DI applicants. We also expect that the states whose WC reforms lead to a greater drop in permanent WC receipt, the type of WC cases that are most likely to have DI as an outside option are likely to see even greater increases in DI applications.

As with Autor and Duggan (2003), we attempt to use policy changes characterizing the generosity of WC benefits. As WC benefits become less generous, injured workers would be more likely to substitute towards DI. We examine several different types of policy changes, drawing on the prior WC literature.

\footnotetext{
${ }^{26}$ We know of no individual level data set that would have the information necessary to identify individual level shifting at the margin. To answer this question, we would need longitudinal data on detailed health and disability status, WC and DI applications, and a sufficient sample size. However, we argue it is the state level analysis that addresses the relevant policy questions, especially the results concerning state WC benefit totals. If it is the more costly individuals at the margin who are driving these trends, the result should be reflected in tests of total benefit dollars.
} 


\subsection{Workers' Compensation Policy Changes}

There are two types of policy changes we consider: those pertaining to the amount of benefits received conditional on acceptance into the program, and those that concern the probability of acceptance into the program. Following the WC literature, we first consider a tightening in WC parameters (see, e.g., Bronchetti and McInerney (2009); Guo and Burton (2010); Guo and Burton (under review); Guo and Burton ( 2008); Butler and Worrall (1983); Butler (1994); Chelius and Kavanaugh (1988); Krueger (1990); Hirsch et al. (1997); and Leigh(1985)). ${ }^{27}$ We use state by year level data and measures of generosity of WC permanent benefits (as these are the individuals most likely to be on the margin between DI and WC programs). ${ }^{28,29}$ In their concurrent work in progress, Guo and Burton (under review) — which updates Guo and Burton (2008) — also examine measures of generosity relevant for permanent WC benefits, but our approaches differ because they almost exclusively examine constructed measures of WC permanent benefit generosity, while we focus on the WC parameters prescribed by regulations and statutes. We restrict ourselves to these measures as our intention is to only examine factors exogenous to the workers but that are under the control of policy makers; it is more difficult to legislate changes to expected benefits than, say, number of weeks that benefits are available.

We examine variation in maximum permanent benefits, including the maximum weekly benefit for permanent benefits and the maximum number of weeks workers can receive permanent benefits. For

\footnotetext{
${ }^{27}$ The prevailing finding in the WC literature is that the more generous WC benefits are, the higher the WC incidence rate. However, Bronchetti and McInerney (2009) find that estimates of worker responsiveness are much smaller than previous estimates suggest after carefully controlling for the impact of a worker's previous earnings, and Guo and Burton (2010) do not find that higher workers' compensation result in higher injury rates.

${ }^{28}$ Bronchetti and McInerney (2009); Hirsch et al. (1997); and Krueger (1990) examine responsiveness to WC benefit generosity using matched March Current Population Survey (CPS) data. Although the matched March CPS data enables researchers to identify transitions into WC, it does not provide the level of detail we need about the type of WC cash benefit received (i.e., TTD, PPD, or PTD benefits) because in the CPS, WC receipt is identified as receiving a positive amount of $\mathrm{WC}$ cash benefits in a given year.

${ }^{29}$ Guo and Burton (2010) examine three measures that describe WC programs. First, they consider the log of the weighted average of cash lifetime benefits received for the four types of WC benefits: temporary total, PPD, PTD, and fatal benefits. They also consider a variable which quantifies statutory changes in eligibility standards. These changes primarily impact those workers with marginal, or less severe injuries. Finally, they consider a measure of the share of workplace injuries reported by the BLS that either received workers' compensation benefits or that did not receive WC because the injured worker returned to work before the state-mandated waiting period passed. They find that workplace injuries are less responsive to benefit generosity than previous estimates suggest.
} 
PPD injuries, we consider maximum values for both scheduled injuries (e.g., loss of an arm) and unscheduled injuries (e.g., persistent lower back pain). The changes in these program parameters are illustrated in Figures 1 and $2 .{ }^{30}$ More details about all the data series used in this paper can be found in the Data Appendix. Recall that since the WC benefit award is a function of a worker's previous earnings, subject to a state maximum, these parameters quantify WC benefit generosity. Although the aggregate trends suggest $\mathrm{WC}$ was becoming more generous over this time period, the national trends obscure changes within a particular state, such as a decline in the maximum weekly PTD benefit from \$1,094 per week in Alaska in 1988 to only $\$ 700$ per week in 1989. These cases are illustrated in Table 1. Though there are some declines in the maximum benefits allowed or in the maximum duration of benefits, the biggest erosion of WC benefit generosity occurs in states where maximum benefits are not increased year to year and do not keep up with inflation.

In addition to these changes in benefit payment amounts, several states enacted other specific reforms to their WC systems in the 1990s in efforts to curb rising WC costs. Most reforms took place in the middle of the decade, and they fall into one of the following four categories. First, eleven states allowed employers, not employees, to select the doctor who first treats an injured worker. Doctors serve as gatekeepers to the WC system, so this reform enables employers to choose physicians who are more conservative about what they consider a valid workplace injury. Seven states began to require objective medical evidence to prove the existence of a workplace injury, making it more difficult for injured workers to receive WC for injuries such as back pain or carpal tunnel syndrome. Nine states enacted reforms which required the workplace injury to be the "major or predominant cause" of the disability. This type of reform especially impacts older workers who may have pre-existing conditions aggravated at work. This would mean that for certain people who used to file for WC (because employment only had to

\footnotetext{
${ }^{30}$ These data were entered by hand from the annual Bureau of Labor Statistics publication, State Workers' Compensation Laws. More details about the data measures used in this paper are available in the Data Appendix.
} 
be a 'material' contributing cause), DI would now be their only recourse. ${ }^{31}$ Finally, 22 states enacted stiff penalties for employees found filing fraudulent claims, which may discourage the marginal WC applicant from claiming benefits.

The existing evidence on the impact of these reforms on the WC program is mixed. Whereas Boden and Ruser (2003) attribute between 7 and 9.4 percent of the decline in days-away-from work injuries that occurred between 1991 through 1997 to those reforms that require objective medical evidence and require the workplace injury to be the major cause of the disability, Ruser et al. (2004) find no impact of these policies on WC claiming, conditional on a workplace injury. Guo and Burton (2010) find that when states made it more difficult for injured workers to be awarded WC benefits in the 1990s, workplace injuries increased whereas WC benefits decreased. These particular policy changes are expected to impact less severe, temporary injuries and not impact permanent WC receipt or DI receipt. However, the enactment of these policy changes in a state may coincide with a shift in the tone of the WC program, so we examine their impact on permanent WC and DI receipt. The timing of these policy reforms is illustrated in Table 1. Most state reforms occurred in the first half of the decade. ${ }^{32}$

The final WC program parameter we examine relates to how an employer's WC premiums are priced. Employer premiums are usually experience rated, thus they are a function of employer size and past losses. Because an employer's premium or cost for WC rises after injuries rise, employers have an incentive to discourage WC claims. Though we do not have data on the premiums faced by employers, we do know the share of a state's WC benefits that was covered by employers who self-insure their WC risks. Self-insuring employers are perfectly experience rated because they absorb the full cost of their workplace injuries. Thus, if employers are acting in ways to discourage WC claims, we would expect to see claims fall as the share of benefits covered by self insuring employers rises. As shown in Table 1, the

\footnotetext{
${ }^{31} \mathrm{See}$ http://www.cbs.state.or.us/wcd/administration/finalmcc.pdf for a case study of the impact of this reform on claiming behavior in Oregon.

32 These data come from Boden and Ruser (2003); Ruser et al. (2004); Tanabe (1998); and Tanabe and Murray (2004).
} 
share of benefits covered by self-insuring employers peaked in 1995 and never fell back to the low of $1992 .^{33}$

A second contribution of our paper is to examine the impact of these parameters describing permanent WC generosity on DI outcomes. To our knowledge, the only other papers to address this question result from concurrent work in progress by Guo and Burton (under review) — which updates Guo and Burton (2008) - and concludes that WC tightening increased DI applications. Our approach differs in two main ways. First, we include year fixed effects to control for national changes over time that may impact SSDI applications. ${ }^{34}$ Second, the measures of WC generosity we study are those prescribed by regulations or statutes, as our intention is to study only those measures likely to be ones that policy makers could change.

\section{Descriptive Analysis}

\subsection{National Trends in Workers’ Compensation and Social Security Disability Insurance}

We now examine the trends in national data series related to WC and DI. First, it is well known that the employment of people with disabilities has fallen dramatically since 1990, as shown in Figure 3. There are many possible reasons for this pattern, including changes in the types of individuals who are of working age and with disabilities (Houtenville and Daly (2003)); changes in the types of work required and the relative competitiveness of those with disabilities (Stapleton, Goodman and Houtenville (2003)); the diminished value of employment because of rising health care costs for the disabled (Hill, Livermore and Houtenville (2003)); changing health profile among the disabled (Kaye (2003)); the Americans with Disabilities Act (DeLeire (2003)); the expansion of federal disability programs in terms of eligibility and

\footnotetext{
${ }^{33}$ We obtained these data on self insurance from the National Academy of Social Insurance publication, "Workers' Compensation: Benefits, Coverage, and Costs."

${ }^{34}$ In fact, when we omit year fixed effects from our main specifications, our results are also more suggestive that tightening in WC leads to increased DI applications, new cases, and benefits. We only present results with year fixed effects in order to better control for changes over time that may impact both DI and WC.
} 
benefits (Goodman and Waidmann, (2003)) as well as the state of the economy (Duggan and Imberman (forthcoming)).

Reflecting this, the DI rolls have risen during the same period, measured both as the number of people on the rolls and total benefit dollars spent, as shown in Figure 4. We consider the total amount spent on DI benefits, as published by the Social Security Administration, and we also consider the number of initial DI applications and initial DI "allowances," what we will refer to as new DI cases, at the state by year level. ${ }^{35}$ These data show that the peak in DI applications happened around 1994, and has declined since then.

While DI outcomes have grown since 1980, WC benefits have fallen. In Figure 5a, we present three measures of WC receipt. We present the total number of workplace injuries with lost workdays from the Bureau of Labor Statistics, and the frequency of PTD and PPD receipt. ${ }^{36}$ In Figure 5a, we show that although the total number of workplace injuries fell much more sharply after 2000, the frequency of WC receipt, as measured by PPD, was lower throughout the 1990s and the early part of this decade than in the 1980s. Interestingly, the number of PTD claims fell in the early 1990s only to rise from 1995 to the present. We include the number of workplace injuries resulting in lost workdays in our analysis as a falsification test. Since only a very small share of workplace injuries are severe enough to result in permanent WC benefits and potentially qualify for DI, we do not expect to see a relationship between DI benefits and workplace injuries, or a relationship between measures of WC generosity for permanent benefits and workplace injuries in our state by year level data.

In Figure 5b, we present measures of spending on WC benefits acquired from the National Academy of Social Insurance. We show that dollars spent on WC benefits, particularly cash benefits, fell

\footnotetext{
${ }^{35}$ Data on DI applications and new cases were generously provided by Richard Burkhauser, Andrew Houtenville and David Stapleton. Data for 1980-1992 were created by Lewin Associates and used in Burkhauser, Butler and Weathers (2002), and Burkhauser, Butler and Gumus (2004). Data for 1993-2001 were created for and used in Houtenville and Burkhauser (2005).

${ }^{36}$ Data on the frequency of PPD and PTD cases were generously provided by John Burton and Steve Guo.
} 
through the first half of the 1990s. Whereas total WC benefits (including cash and medical) rose in the early part of this decade, the amount spent on cash benefits continued to fall. This decline in WC cash benefit spending during a time of rising DI benefit spending may reflect substitution between the two programs. $^{37}$

These figures provide a sense of the magnitude of the total number of DI and WC recipients and total benefit dollars spent at the national level, but they do not describe the situation at the state level. In Table 2, we present summary statistics for our measures of WC and DI receipt at the state level. So that we can make comparisons across states of different sizes, throughout the rest of the paper we present all measures of WC and DI receipt per 100,000 workers in a state and year. First, we see that workplace injuries with lost workdays are far more common than the permanent cases most likely to view DI as a substitute. Whereas there is an average of nearly 3,000 cases of workplace injuries with lost workdays (per 100,000 workers) per year at the state level, we see, on average, only seven PTD cases (per 100,000 workers) and 560 PPD cases (per 100,000 workers). When we compare the WC claim frequency with DI claim frequency, we find that DI cases are much more common than the severe WC claims. There are more than 1,000 applications to DI per 100,000 workers, resulting in over 400 new DI cases per 100,000 workers.

We also present measures of spending for the two programs. When we consider all WC benefit spending (i.e., medical benefits as well as cash benefits for temporary, permanent, and fatality cases), spending on the two programs appears to be rather similar. By this measure, both WC and DI spend between $\$ 40$ and $\$ 50$ million per 100,000 workers. ${ }^{38}$ However, our DI benefit spending measure does not

\footnotetext{
${ }^{37}$ Note that the negative relationship between WC and DI is not as clear as in the two series per $\$ 100$ in covered wages published in the National Academy of Social Insurance (NASI) publications that present DI and WC benefits. When we do not divide benefits by covered wages, we only see a negative relationship between the two programs during the 1990s. In contrast, the NASI data, presented per $\$ 100$ in covered wages, suggest a negative relationship from 1980 to 2007. We do not present results by covered wages because data on covered wages are not available to us at the state level, nor are these data available at the national level prior to 1989.

${ }^{38}$ This corresponds to between $\$ 400$ and $\$ 500$ per worker. Given that there are approximately 100 million workers per year, aggregating up yields total benefits on the order of $\$ 40$ or $\$ 50$ billion, what we see in the aggregate national statistics.
} 
include any medical benefits, so a more appropriate comparison would be to compare WC cash benefit spending and DI benefit spending. State-level data on WC cash benefit spending is available beginning in 1996, and we see states spend an average of \$20 million per 100,000 workers, versus DI program spending of nearly $\$ 50$ million per 100,000 workers. ${ }^{39}$ This difference actually understates the discrepancy between the two programs because we argue that it is permanent $\mathrm{WC}$ benefit recipients who are most likely to substitute DI for WC, and the measure of WC cash benefits also includes payments to temporary and fatal WC benefit recipients. We do not know of a data series that separates WC cash benefit spending by injury type and state, so this calculation is not possible. ${ }^{40}$

In the second half of Table 2, we also present summary statistics of the WC program parameters examined in this paper. WC programs provide the most generous benefits to injured workers receiving PTD benefits. The average state sets maximum PTD benefits at $\$ 525$ per week for a maximum of over 900 weeks. In contrast, the average state sets maximum PPD benefits at nearly $\$ 440$ per week for a maximum of only 600 weeks. Perhaps injured workers do not respond to the generosity of either one of these parameters individually, but to the maximum amount they can expect to receive from WC for their injury. The average maximum amount for unscheduled PPD claim is just over \$260,000. PPD benefits for specific, scheduled injuries are even less generous. Workers who lose an arm may receive benefits for an average of 400 weeks, and total payments for the loss of an arm are not to exceed $\$ 175,000$. In the last section of Table 2, we quantify the reforms states enacted to lower WC costs. By far the most common types of reform were to either allow a worker's employer to choose the treating doctor or establish stiff penalties for fraudulent claims. We also show that approximately 23 percent of benefits are covered by self-insuring employers at the state by year level.

\section{Regression Results}

\footnotetext{
${ }^{39}$ When we consider DI spending from 1996 to 2006, the discrepancy is even larger. During this period, DI benefits total over $\$ 56$ million per 100,000 workers.

${ }^{40}$ The Workers' Compensation Policy Review publishes series of incurred cash benefits by injury type and state; however, incurred cash benefits do not represent the amount paid out in benefits in a particular year. Instead, incurred benefits represent the amount expected to be paid out over the life of a claim. Therefore, they are not comparable to the published measures of spending for the DI program.
} 


\subsection{The Relationship Between Security Disability Insurance Outcomes and Workers' Compensation}

\section{Outcomes}

Recall that our hypothesis is that workers whose situations allow them to have both DI and WC as options are more likely to apply for DI when their WC net expected benefits are reduced either because WC benefit parameters fall or through the specific state reforms we have described. Because of the offset rules described earlier, injured workers may apply for DI as a full substitute, or as a supplement to WC. While the national trends shown in Figures 4 and 5 suggest there may be a connection between the two programs, regression analysis will show whether the relationships between WC and DI series persists at the state by year level once state and year fixed factors are accounted for, and whether there may be a causal link that comes from exogenous policy changes in WC affecting DI outcomes.

First, we examine whether the national time trend relationship between WC and DI hold up at the state level; since policies for WC are set by states, the correlation should show up at the state level to be consistent with the possibility of a causal connection between the two programs. We do so by regressing our state level measure of DI receipt on a state level measure of WC receipt, both measured at the annual level. We start with a regression with no other controls except state and year fixed effects in specification (1), and then add more controls in specification (2).

(1) $D I_{s, t}=\beta_{0}+\beta_{1} W C_{s, t}+\mu_{s}+\tau_{t}+\varepsilon_{2, s, t}$

DI and WC stand for the different measures of DI and WC receipt illustrated in Figures 4 and 5 and Table 2. We estimate (1) using alternative measures of DI and WC to be thorough in testing for this relationship. We include state and year effects to control for time invariant state characteristics as well as national time trends that would affect both programs, such as the aging of the population. This allows us to examine the relationship between the WC and DI series within a state, which is our question of interest.

In (2) we also control for several state-level factors that might shift how attractive WC or DI benefits are to a given state's population. First, we consider a measure of macroeconomic conditions, the state-level 
unemployment rate. As shown in Autor and Duggan (2003), DI receipt is positively correlated with unemployment for individuals considering applying for DI. Rising unemployment might also make WC a more attractive option for workers in jeopardy of layoffs. Workplace injury rates - and the type of workplace injuries - vary across industries, so we also control for the share of a state's workforce in the following industries: agriculture; mining; construction; manufacturing-durable goods; manufacturingnondurable goods; transportation; wholesale trade; retail trade; finance, insurance, and real estate; business and repair services; personal services; and professional services. To the extent a safer work climate reduces workplace injuries that may result in $\mathrm{WC}$, and ultimately $\mathrm{DI}$, omitting controls for workplace composition imposes an upward bias on our measure of WC receipt. Finally, we also control for the state's demographic composition. An older population may be more at risk for DI and permanent WC benefits, so we include the share of the state population ages 45 to 54 and ages 55 to 64 . Workers are most prone to workplace injuries when beginning a new job, so an increase in the state's population may suggest an influx of workers. Therefore, we also include the number of workers ages 25 to 64 (in millions). Thus, our final specification for testing the time series correlation between DI and WC at the state level is:

(2) $D I_{s, t}=\gamma_{0}+\gamma_{1} W C_{s, t}+\gamma_{2}$ unem $_{s, t}+\gamma_{3}$ share $45 \_54_{s, t}+\gamma_{4}$ share $55_{-} 64_{s, t}+\gamma_{5}$ pop $25_{-} 64_{s, t}+$ $\Psi_{s, t}+\mu_{s}+\tau_{t}+\varepsilon_{3, s, t}$

where $\Psi_{\mathrm{s}, \mathrm{t}}$ is a vector of the share of workers employed in different industries, and other variables are as indicated by labels.

The results from (1)-(2) are presented in Table 3. In Panel 1, we present coefficients from 15 separate regressions where we regress each of our three measures of DI receipt on each of our five measures of $\mathrm{WC}$ receipt, as in equation (1). Since there are so many different measures of WC and DI receipt, we examine the relationship between all possible pairings, including applications, case counts, workplace injuries, and benefit dollars spent. Of these 15 pairs of series, we find that only three of them have a 
statistically significant, negative relationship (DI applications with workplace injuries, new DI cases with workplace injuries, and DI spending with workplace injuries) and one has a statistically significant positive coefficient (DI applications with WC cash benefit spending). In Panel 2, we add controls that might shift how attractive WC or DI are in a particular state, and find though the coefficient is still negative in those three cases above, only the coefficients on workplace injuries with new DI cases or DI benefit spending remain statistically significant. There are two things to note about these two out of 15 cases that are statistically significant and negative. The vast majority of work place injuries are not of the severity that would qualify for federal DI, thus it is unlikely that this is the measure of WC related outcomes where a causal relationship would occur, of all the possibilities we explore. Second, the magnitude is quite small; the coefficient estimate implies that each additional workplace injury (per 100,000 workers) corresponds with only a $\$ 5,000$ decline in DI benefits, a reduction of less than one thousandth of one percent. ${ }^{41}$ Thus, these results in Table 3 suggest that despite the aggregate WC and DI trends illustrated in Figures 4 and 5 which look to be negatively correlated, within a given state the story is much different and there appears to be little relationship between WC and DI series. To illustrate this point graphically, our Appendix 2 shows scatterplots of the relationship between changes in DI and changes in WC. Simply put, although there is a concurrent rise in DI and fall in WC at the national level, the rises in DI and falls in WC do not come from the same states, thus it is unlikely that the changes observed are causal since WC rules are set by states and would be expected to change the DI outcomes in that state, not in a different state.

It is possible that studying DI and WC correlations may show a lack of correlation because WC

\footnotetext{
${ }^{41}$ A possible objection to our method of analysis is that 1980 to 2006 may not be the appropriate time period because the negative relationship we document in Figures 4 and 5 only appears in the 1990s. We also ran these 45 regressions for the years 1990 onward and the results are qualitatively similar. We also considered the possibility of a lag between the two programs. That is, perhaps WC receipt needs to fall for a year or two before we see changes in DI receipt because eligibility for DI benefits requires an extended period of disability. In both programs, there may be lags between the initial date when workers are eligible for benefits and the date when benefits actually begin. This is particularly true for workers with serious injuries who apply for PPD or PTD benefits, where there are often administrative delays. Therefore, we also ran these 45 regressions with $\mathrm{WC}$ receipt lagged one and two years. The only qualitative difference in the results is that when we lag WC receipt by one year, there is one negative, statistically significant relationship between PTD cases and new DI cases in our third specification. Given this is just one of many regressions, we do not read too much into this one statistically significant coefficient.
} 
and DI trends are not causally connected, or it may be that considering the aggregate trends obscures the component of the variation in $\mathrm{WC}$ that is policy driven. We next consider tests of whether changes in WC program parameters impact WC receipt, and then whether those changes in WC parameters impact DI receipt.

\subsection{The Effect of Workers' Compensation Program Parameters on Workers' Compensation Outcomes}

Before we can examine the causal impact of WC program parameters on DI receipt, we first must establish that permanent $\mathrm{WC}$ receipt is responsive to those program changes as a direct effect. We proceed by regressing our measures of WC receipt on one of the parameters describing WC program generosity. We repeat the regression for each of our measures of WC generosity.

(3) $W C_{s, t}=\delta_{0}+\delta_{1} W C_{-}$generosity $_{s, t}+\delta_{2}$ unem $_{s, t}+\delta_{3}{\text { share } 45 \_54_{s, t}+\delta_{4} \text { share55_64 }}_{s, t}+$ $\delta_{5}$ pop25_64 $4_{s, t}+\Psi_{s, t}+\mu_{s}+\tau_{t}+\varepsilon_{4, s, t}$

In Table 4, we present the estimated coefficient of interest from 75 different regressions. We regress each of our five measures of WC receipt on each of our 14 measures of WC generosity, one at a time. In each case, the dependent variable is a measure of WC receipt. These include: the frequency of WC claims with the number of workplace injuries in a given year (per 100,000 workers); the number of PTD and PPD cases in a given year (per 100,000 workers); measures of dollars spent on WC (WC cash and medical benefits (per 100,000 workers, in thousands) as well as WC cash benefits (per 100,000 workers, in thousands)). The 14 different measures of WC generosity are explained in the rows of the table. In Panel A of Table 4, we examine changes to legislated parameters for permanent WC benefits, such as the maximum weekly benefit for PTD and PPD injuries, or the maximum number of weeks an injured workers may receive either of these benefits. Recall PPD benefits may be either scheduled or unscheduled, so we separately consider provisions governing those two types of permanent benefits. First, we incorporate the maximum PPD benefit for unscheduled injuries, and for a representative scheduled injury - the loss of an arm —we consider the maximum number of weeks workers may receive PPD 
benefits and the maximum total dollar value of those benefits. In Panel B of Table 4, we examine three measures of WC generosity together: the maximum weekly benefit for PTD injuries, maximum total benefits for unscheduled PPD injuries, and the maximum number of weeks an injured worker may receive benefits for the loss of an arm. We include this specification in case together these three measures better capture WC generosity in a given state. A positive relationship between the WC benefit generosity parameters and the WC outcome measures is consistent with these measures of generosity impacting WC receipt.

First, we discuss the results in Table 4 concerning workplace injuries. Recall we do not expect to find much of a relationship between generosity for permanent WC benefits and workplace injuries because only a few workplace injuries will result in permanent benefits and perhaps be severe enough to qualify for DI. In Panels A and B, we only find four positive, statistically significant relationships between measures of WC generosity and the number of workplace injuries, per 100,000 workers (out of 11 possibilities). First, a $\$ 10$ increase in the maximum weekly PTD benefit corresponds to between four and five additional workplace injuries (per 100,000 workers). However, it is not surprising to find a positive, statistically significant effect because in many states, the maximum weekly PTD benefit is the same as the maximum weekly benefit for temporary injuries, the first type of WC benefit injured workers receive (and the most common type of cash benefit claim). This qualitative conclusion holds whether we include the maximum weekly PTD benefit on its own or with other benefit generosity parameters, as in Panel B. ${ }^{42}$ We also find that if a state allows ten additional weeks of benefits for the loss of an arm, there will be between 2.5 and 3 more workplace injuries (per 100,000 workers), a conclusion that also holds whether the parameter is considered on its own or with other measures of WC generosity, as in Panel B. This estimate is trivial and corresponds to an increase of less than one tenth of one percent.

As we focus our attention on measures of permanent WC outcomes, we evaluate each estimated

\footnotetext{
${ }^{42}$ Note that in Panel B, the estimated coefficients on the WC policy parameters are jointly significant in column (1), where the dependent variable is workplace injuries.
} 
relationship as a candidate for explaining the aggregate decline in WC benefits. First, we must determine whether there is a positive, statistically significant relationship between the measure of WC benefit generosity and the WC outcome. Second, for the statistically significant coefficient estimates, we next assess the magnitude of the relationship because a small response is unlikely to drive the aggregate decline in WC receipt. Finally, if the relationship is statistically significant and the response is of a sizable magnitude, we determine how prevalent changes to that parameter were. If a WC parameter appears to impact WC receipt, the magnitude is sizable, but we document only a few instances of that particular parameter changing, then it is unlikely to explain the aggregate trends we observe in the national data.

In column (2), we examine PTD claims (per 100,000 workers), and we see very little responsiveness to WC generosity. The only statistically significant results in Panels A and B are that each additional 100 weeks in benefits for the loss of an arm results in one additional PTD claim (per 100,000 workers). However, this finding is unlikely to explain the aggregate decline in WC benefit receipt because we document only ten declines in maximum duration for the loss of an arm. This may be because workers are not responsive to benefit generosity (see, e.g., Bronchetti and McInerney (2009) or Burton and Guo (2010)), or this may arise if there is too little variation in the number of PTD claims (per 100,000 workers) within a state over time. In column (3), among PPD claims, we do see modest responsiveness to benefit generosity. Notably, injured workers appear to respond to the weekly maximum of PPD benefits. When maximum weekly benefits increase by $\$ 10$ for PPD injuries, we see on average four additional PPD claims per 100,000 workers, an increase of less than one tenth of one percent from the mean number of PPD claims in a state, 560. It does not appear that any of the benefit generosity parameters are driving the decline in PPD claims, either, because the policy changes that seem to matter occur only rarely or because the magnitude of the impact is small, even if it is statistically significant.

We also find some modest responsiveness to WC spending and WC benefit generosity parameters; however, in each case the WC parameter changes only rarely, meaning it is unlikely such changes drive the aggregate trends. When the maximum PPD weekly benefit is higher, states spend more 
on all WC benefits (medical and cash benefits) as well as more on WC cash benefits. A \$10 increase in the maximum weekly benefit for PPD injuries corresponds with nearly $\$ 325,000$ in additional cash and medical benefits paid for WC (per 100,000 workers) and nearly \$203,000 more in additional cash benefits paid for WC. These statistically significant relationships are of a sizable magnitude; however, we document only 24 instances of states reducing (or failing to increase) maximum weekly PPD benefits over the 21 years between 1984 and 2005 (see Table 1). ${ }^{43}$ Some states do not set a cap on PPD benefits for unscheduled injuries, so in the bottom row of Panel A we include a dummy variable that equals one in states and years where there is no maximum. We find that in such states, WC cash and medical spending is nearly $\$ 6$ million, or 14 percent higher. However, we only document six instances of states imposing a maximum on PPD benefits, so this result on its own is also unlikely to explain the aggregate trends in WC.

In Panel $\mathrm{C}$ of Table 4, we examine other changes to the WC system that occurred during the 1990s and may have impacted the probability a workplace injury would qualify for WC. We consider those policy reforms proposed by Boden and Ruser (2003) and Ruser et al. (2004), as well as the share of benefits in a state covered by self insurance. These policy reforms are expected to have the biggest impact on minor, temporary workplace injuries, but we include them in case they reflect changes in the tone of a state's WC system that would also discourage more serious, permanent workplace injuries that might eventually qualify for DI. As with previous research, we find little impact of these policy reforms on WC claiming. A negative relationship between states that implement these policies and WC receipt would be consistent with WC policy reforms impacting WC receipt, and we only find two negative, statistically significant results. As in Boden and Ruser (2003), we find modest evidence that the number of workplace injuries in a given state and year is negatively correlated with policy reforms to rule out "nonwork impacts"- or require the workplace injury to be the major cause of the disability. States implementing

\footnotetext{
${ }^{43}$ We also see this positive relationship between WC cash and medical benefits and the total benefits available for PPD. When maximum PPD benefits for unscheduled injuries are increased by $\$ 1,000$, WC benefit spending increases by between $\$ 13,000$ and $\$ 14,000$ (per 100,000 workers), an increase of less than one tenth of one percent.
} 
such policies see nearly 200 fewer workplace injuries per year, on average, or a 6.7 percent reduction.

This result is also not surprising because this measure of WC system change likely dissuades injured workers with the most marginal injuries from receiving WC (or reporting a workplace injury). We also find states that enact stiff penalties for fraudulent claims have 3.6 fewer PTD claims per 100,000 workers.

These results in Table 4 suggest WC receipt may be modestly responsive to some measures of WC generosity, though the response is quite muted and not on the order found in previous research (e.g., Krueger (1990) finds a ten percent increase in WC benefits leads to a 7.4 percent increase in WC claims). ${ }^{44}$ This may be because moral hazard is less of an issue for the more serious, permanent injuries, or because labor supply disincentives in WC are smaller than previously estimated (Bronchetti and McInerney (2009); Guo and Burton (2010)). This result may also arise merely because with so many regressions estimated, some relationships may be statistically significant by chance (see, e.g., Bland and Altman (1995)). Chance could also explain why we see two negative, statistically significant relationships between measures of WC generosity and WC cash benefit spending (and one positive, statistically significant relationship between a WC reform and WC cash benefit spending). ${ }^{45}$

\subsection{Effect of Workers' Compensation Program Parameters on SSDI Outcomes}

We next explore the effect of WC program parameters on DI receipt to assess whether changes in WC generosity impact DI claims. We regress our measure of DI receipt on the different parameters describing WC generosity.

(4)

$$
\begin{aligned}
& D I_{s, t}=\theta_{0}+\theta_{1} W C_{-} \text {generosity }_{s, t}+\theta_{2} \text { unem }_{s, t}+\theta_{3} \text { share } 45_{-} 54_{s, t}+\theta_{4} \text { share } 55_{-} 64_{s, t}+ \\
& \theta_{5} \text { pop } 25_{-} 64_{s, t}+\Psi_{s, t}+\mu_{s}+\tau_{t}+\varepsilon_{5, s, t}
\end{aligned}
$$

\footnotetext{
${ }^{44}$ As with the regressions estimating the relationship between DI and WC receipt, in results not shown we consider the 1990s onward and we lag the WC generosity parameters by one and two years, respectively. The results are qualitatively the same. Results available on request.

${ }^{45}$ In fact, when we apply the Bonferroni adjustment that has been recommended for such situations and set our threshold for statistical significance at the conventional level divided by the number of different regressions run, or $.10 / 75=.0013$ in our case, only one of the relationships retain statistical significance — in Panel B, weeks of benefits for loss of an arm is positively and statistically significantly correlated with the number of workplace injuries. We do not place much weight on this finding because we do not expect workplace injuries to respond to this parameter.
} 
The results for this exercise are shown in Table 5. Again, we present results from 45 separate regressions and three different dependent variables: the number of DI applications (per 100,000 workers); the number of new DI cases (per 100,000 workers); and the amount spent on DI benefits (per 100,000 workers, in thousands, in 2000 \$). We first focus on those program parameters quantifying benefit generosity that were shown to impact WC receipt in Table 4. A negative relationship between these measures of WC program generosity and DI receipt would be consistent with a causal link between the two programs. Only a few of these conditional relationships are statistically significant, yet the magnitudes are very small. For example, a $\$ 10$ increase in the maximum weekly PTD benefit would yield 1.5 fewer applications to DI, a reduction of only one hundredth of one percent. Similarly, a $\$ 10,000$ increase in total allowable PPD benefits for unscheduled injuries yields only one fewer application to DI.

The responses are similarly muted when we examine new DI cases or actual benefits paid, measures that quantify actual DI receipt and not just applications. In Panel B of column 3 we show that a $\$ 10$ increase in the maximum weekly PTD benefit corresponds with a $\$ 93,000$ decrease in real DI benefits per 100,000 workers, a decline of only two tenths of one percent. ${ }^{46}$

We also see a modest relationship between DI receipt and some of those WC parameters that did not impact WC receipt. We are interested in these relationships if, for example, the WC parameters impact the duration of WC receipt or make injured workers more likely to claim both WC and DI. Since in most states, DI benefits are reduced when individuals receive benefits from both programs, we might see a shift in DI benefits even when we did not see the change in WC benefits. A few of these relationships are statistically significant but have modest economic impacts. For example, a 100 week increase in the maximum duration of PPD benefits yields seven fewer DI applications. Similarly, each additional week injured workers may receive benefits for the loss of an arm yields an $\$ 8,000$ reduction in real DI spending per 100,000 workers (a reduction of only two hundredths of one percent).

\footnotetext{
${ }^{46}$ Note that for each of the DI outcomes considered in Table 5, the three WC policy parameters in Panel B are always jointly significant.
} 
In Panel C, we present results from regression estimates of WC policy changes on DI claiming. A positive coefficient would suggest that as WC programs tightened, injured workers turned to the DI program. Only one coefficient is positive and statistically significant; states enacting any of the reforms see a $\$ 1.2$ million increase in DI spending per 100,000 workers. ${ }^{47}$ We hesitate to place too much emphasis on the results in Table 5-and the relationship between "any WC policy" and DI spending, in particularbecause as with the regressions of WC receipt on WC parameters, a handful of statistically significant results may arise due to chance. ${ }^{48}$

As with Table 3, we argue that it is important to consider whether changes in WC rules and DI are happening within the same state over time, thus our rationale for including state by year fixed effects.

However, we are careful to consider whether the lack of results simply represents a change in coefficients or simply an increase in standard errors once we include these fixed effects. If it is only a change of standard errors, this could be consistent with a potential existence of a causal relationship that we are unable to detect with the amount of actual variation that occurred in the WC parameters. We rule this out in two ways. First, the standard errors are of approximately the same magnitude when we exclude state or year fixed effects (as when we include both state and year fixed effects); instead, the difference comes in coefficient magnitudes. Second we display scatterplots of the change in DI and change in WC rules at the state level (as we did for Table 3) and demonstrate that it is not the case that changes in WC and changes in DI come from the same states.

\section{Discussion and Conclusion}

In this paper, we start by showing how at the national level, total spending on two of the largest social insurance programs, WC and DI were moving in opposite directions during the 1990s. WC and DI

\footnotetext{
${ }^{47}$ As with the other analyses, we also separately consider the 1990s and lag the WC parameters by one or two years. As with our baseline specifications, the magnitudes are quite small and our qualitative conclusions do not change. Results available upon request.

${ }^{48}$ When we apply the Bonferroni adjustment and set our threshold for statistical significance at $.10 / 45=.002$, only two statistically significant relationships remain. We find that when the weekly maximum for PTD is higher, there are fewer DI applications and new cases.
} 
are two major programs that pay for costs associated with ill health, aside from traditional forms of private and public medical insurance. This negative relationship between the $\mathrm{WC}$ and DI trends has prompted speculations as to whether there was an increase in reliance on DI (a federal program) as a direct result of tightening of state WC programs. We show that the movement in opposite directions of the aggregate national trend does not hold once one looks within states, the level at which a causal story could be told. A causal relationship may still exist where WC tightening leads to a growth in DI rolls, despite no correlation being found in the magnitude of the two programs over time at the state level. Thus, we next test whether WC policy changes that reduce the generosity of the program have a causal effect on WC (first) and DI outcomes (subsequently) at the state level. We find no statistically significant evidence in the overwhelming majority of our tests; there are a few cases of statistically significant results of relatively small magnitudes, ${ }^{49}$ but since this could arise due to pure chance when running many regressions, ${ }^{50}$ on net, our results suggest that it is unlikely that substitution between these programs is present and contributing substantially to the decline in employment of working-age individuals with disabilities.

We acknowledge that at the micro level, for certain individuals at the margin, it is still possible that changes in WC generosity may affect DI applications. However, we argue that our approach answers the relevant policy question that the decline in WC outcomes observed in the national trends during the 1990s is not a significant factor in the increase in DI receipt and the fall in employment rates among working aged people with disabilities during the same period.

\footnotetext{
${ }^{49}$ For example, when PPD maximum benefits for unscheduled injuries are increased by $\$ 1,000$, WC benefit spending increases by between $\$ 13,000$ and $\$ 14,000$ (per 100,000 workers), an increase of less than one tenth of one percent. We also find at best only modest evidence that changes in WC generosity impact DI receipt, and again, the magnitudes implied by any coefficients that are statistically significant are quite small. We find that a $\$ 10,000$ increase in total allowable PPD benefits for unscheduled injuries yields only one fewer application to DI. ${ }^{50}$ The fact that there are any statistically significant results at all should be viewed in the context of the multiple parameters and outcomes we consider. In Table 4, only 14 coefficient estimates out of 75 regressions are statistically significant and consistent with WC receipt responding to WC parameters. In Table 5, only 9 coefficient estimates out of 45 regressions are statistically significant and consistent with DI receipt responding to WC parameters. When we apply a Bonferroni adjustment (to account for the fact that just by chance some coefficients will be statistically significant), these numbers reduce to one statistically significant relationship between WC parameters and WC outcomes and two statistically significant relationships between WC parameters and DI outcomes.
} 


\section{Works Cited}

Acemoglu, Daron and Joshua D. Angrist. (2001) "Consequences of Employment Protection? The Case of the Americans with Disabilities Act.” The Journal of Political Economy, 109(5): 915-957.

Autor, David and Mark Duggan. (2003) "The Rise in the Disability Rolls and the Decline in Unemployment," Quarterly Journal of Economics, February: 157-206.

Barth, Peter. (2005) “Compensating Workers for Permanent Partial Disabilities," Social Security Bulletin, 65(4).

Bland, JM and DG Altman. (1995) "Multiple Significance Tests: The Bonferroni Method," BMJ, 310:170.

Boden, Leslie I. and John W. Ruser. (2003) 'Workers' Compensation 'Reforms,' Choice of Medical Care Provider, and Reported Workplace Injuries," The Review of Economics and Statistics, 85(4): 923-929.

Bound, John and Richard V. Burkhauser. (1999) "Economic Analysis of Transfer Programs Targeted on People with Disabilities." In Orley C. Ashenfelter and David Card (eds.), Handbook of Labor Economics. Volume 3C. Amsterdam: Elsevier Science, pp. 3417-3528.

Bronchetti, Erin Todd and Melissa Powell McInerney. (2009) "Revisiting Incentive Effects in Workers' Compensation: Do Higher Benefits Really Induce More Claims?" Mimeo. College of William and Mary.

Burkhauser, Richard V., J.S. Butler and Gulcin Gumus. (2005a) "A Dynamic Programming Model of Social Security Disability Insurance Application,” Journal of Applied Econometrics, 19(6): 671-685.

Burkhauser, Richard V., Andrew J. Houtenville, and Ludmila Rovba. (2005b) "Rising Poverty in the Midst of Plenty: The Case of Working-Age People with Disabilities." Ithaca, NY: Cornell University, Rehabilitation Research and Training Center for Economic Research on Employment Policy for People with Disabilities. http://digitalcommons.ilr.cornell.edu/edicollect/162.

Burkhauser, Richard V., J.S. Butler, and Robert R. Weathers II. (2002) "How Policy Variables Influence the Timing of Social Security Disability Insurance Applications," Social Security Bulletin, 64(1): 52-83.

Burkhauser, Richard V., J. S. Butler, and Yang W. Kim. 1995. "The Importance of Employer Accommodation on the Job Duration of Workers with Disabilities: A Hazard Model Approach." Labour Economics. 2(June):109-30

Burkhauser, Richard V., J. S. Butler, Yang W. Kim, and Richard R. Weathers. 1999. "The Importance of Accommodations on the Timing of Disability Insurance Applications: Results from the Survey of Disability and Work and the Health Retirement Study." Journal of Human Resources 34 (Summer):589611

Butler, Richard F. and John D. Worrall. (1983) "Workers' Compensation: Benefit and Injury Claims Rates in the Seventies," The Review of Economics and Statistics, 65(4): 580-589.

Butler, Richard F. (1994) "The Economic Determinants of Workers' Compensation Trends," Journal of Risk and Insurance, 61(3): 383-401. 
Burton, John F., Jr. and Emily Speiler. (2001) "Workers' Compensation and Older Workers. Health and Income Security for an Aging Workforce," Brief No. 3 (Washington, DC: National Academy of Social Insurance).

California Division of Workers' Compensation. (2009) "California Division of Workers' Compensation fact sheet D: Answers to your questions about permanent disability benefits" viewed at http://www.dir.ca.gov/DWC/iwguides.html on September 7, 2009

Campolieti, Michele. 2004. "The Correlates of Accommodations for Permanently Disabled Workers." Industrial Relations 43(July):546-72

Chelius, James R. and Karen Kavanaugh. (1988)'Workers' Compensation and the Level of Occupational Injuries," Journal of Risk and Insurance, 55(2): 315-323.

Daly, Mary C. and Andrew Houtenville. (2003) "Employment Declines Among People with Disabilities." In David Stapleton and Richard Burkhauser (eds.) The Decline in Employment of People with Disabilities: A Policy Puzzle. Upjohn Press, March 2003.

Daly, Mary C., and John Bound. 1996. "Worker Adaptation and Employer Accommodation Following the Onset of a Health Impairment." Journal of Gerontology: Social Sciences 51B(March):S53-60

DeLeire, Thomas (2000) "The Unintended Consequences of the Americans with Disabilities Act." Regulation, 23(1): 21-24.

DeLeire, Thomas. (2000) "The Wage and Employment Effects of the Americans with Disabilities Act." Journal of Human Resources, 35(4): 693-715.

DeLeire, Thomas. (2003) "The Americans with Disabilities Act and the Employment of People with Disabilities." In David C. Stapleton and Richard V. Burkhauser (eds.) The Decline in Employment of People with Disabilities: A Policy Puzzle. Kalamazoo, MI: W.E. Upjohn Institute.

Duggan, Mark and Scott Imberman. (forthcoming) "Why are the DI Rolls Skyrocketing? The Contribution of Population Characteristics, Program Changes, and Economic Conditions," in Health in Older Ages: The Causes and Consequences of Declining Disability Among the Elderly, David Cutler and David Wise (editors). University of Chicago Press.

Fishback, Price V. and Shawn Everett Kantor. (2000) A Prelude to the Welfare State: The Origins of Workers' Compensation. National Bureau of Economic Research Series on Long-Term Factors in Economic Development.

Galizzi, Monica, Petra Miesmaa, Laura Punnett, Craig Slatin, and The Phase In Healthcare Research Team. (2010) "Injured Workers' Underreporting in the Health Care Industry: An Analysis Using Quantitative, Qualitative, and Observational Data." Industrial Relations, 49(1): 22-43.

Goodman, N. and T. Waidmann. (2003) "Social Security Disability Insurance and the Recent Decline in the Employment Rate of People with Disabilities," in The Decline in Employment of People with Disabilities: A Policy Puzzle. David C. Stapleton and Richard V. Burkhauser (eds.). Kalamazoo, MI: W.E. Upjohn Institute. 339-368. 
Gruber, Jonathan and Jeffrey Kubik. (1997) "Disability Insurance Rejection Rates and the Labor Supply of Older Workers," Journal of Public Economics, 64: 1-23.

Guo, Xuguang (Steve) and John F. Burton Jr. (2008) “The Relationship Between Workers' Compensation and Disability Insurance." In Adrienne E Eaton (ed), Proceedings of the $60^{\text {th }}$ Annual Meeting.

Champaign, IL: Labor and Employment Relations Association.

Guo, Xuguang (Steve) and John F. Burton, Jr. (2010) "Workers' Compensation: Recent Developments in Moral Hazard and Benefit Payments." Industrial and Labor Relations Review, 63 (2):

Guo, Xuguang (Steve) and John F. Burton, Jr. (under review) "The Growth of SSDI Recipients: A Spillover Effect from Workers’ Compensation,” mimeo, Rutgers University.

Hill, C., G. Livermore, and A. Houtenville. (2003) "Rising Health Care Expenditures and the Employment of People with High-Cost Chronic Conditions." In D. Stapleton and R. Burkhauser (eds.), The Decline in Employment of People with Disabilities: A Policy Puzzle. Kalamazoo, MI: W.E. Upjohn Institute for Employment Research.

Hirsch, Barry T., David A. Macpherson, and J. Michael Dumond. (1997) "Workers' Compensation Recipiency in Union and Nonunion Workplaces," Industrial and Labor Relations Review, 50(2): 213-236.

Houtenville, Andrew, and Richard B. Burkhauser. (2004) "Did the Employment of People with Disabilities Decline in the 1990s, and Was the ADA Responsible? A Replication and Robustness Check of Acemoglu and Angrist (2001)", Research Brief (Ithaca, NY, Cornell University Employment and Disability Institute)

Kaye, H.S. (2003) "Improved Employment Opportunities for People with Disabilities." National Institute on Disability and Rehabilitation Research. Available at http://www.dsc.ucsf.edu/pdf/report17.pdf.

Krueger, Alan B. (1990) “The Incentive Effects of Workers' Compensation,” Journal of Public Economics. 41: 73-99.

Krueger, Alan B. and Bruce D. Meyer. (2002) “Labor Supply Effects of Social Insurance,” NBER Working Paper 9014.

Leigh, J. Paul. (1985) “Analysis of Workers' Compensation Using Data on Individuals.” Industrial Relations. 24(2): 247-256

Livermore, Gina, David Stapleton, and Henry Claypool. (2009) "Health Insurance and Health Care Access Before and After SSDI Entry: Final Report.” Mathematica Policy Research.

Lockhart, III, James B. (2005) "Reassessing the Relationship Between Disability Insurance and Workers' Compensation." Social Security Bulletin, 65(4).

Meyer, Bruce D. (2002) “Unemployment and Workers' Compensation Programs: Rationale, Design, Labor Supply and Income Support.” Fiscal Studies, 23(1): 1-49.

Mont, Daniel, John F. Burton, and Virginia Reno. (2000) Workers' Compensation: Benefits, Coverage, and Costs, 1997-1998, New Estimates. Washington, DC: National Academy of Social Insurance. 
Reno, Virginia, Cecili Thompson Williams, and Ishita Sengupta. (2005) "Workers' Compensation, Social Security Disability Insurance, and the Offset: A Fact Sheet.” Social Security Bulletin, 65(4).

Reville, Robert T. and Robert F. Schoeni. (2005) "The Fraction of Disability Caused at Work," Social Security Bulletin, 65(4).

Roberts, Karen. (1994) “The Role of Supplemental Disability Benefits in Income Security for Injured Workers.” Industrial Relations, 33(3): 365-376.

Ruser, John W., Michael Pergamit, and Parvati Krishnamurty. (2004) "Workers' Compensation 'Reforms' and Benefit Claiming.” U.S. Bureau of Economic Analysis Working Paper.

Schur, L., D. Kruse, J. Blasi, and P. Blanck. 2009. "Is Disability Disabling in All Workplaces? Workplace Disparities and Corporate Culture". Industrial Relations. Volume 48 Issue 3, Pages 381 - 410

Social Security Administration. (2008) "Chart 11: Final outcome of disabled worker applications, 19982007." Annual Statistical Report on the Social Security Disability Insurance Program, 2008. Social Security Administration. Available at http://www.ssa.gov/policy/docs/statcomps/di asr/2008/sect04.html. Viewed September 7, 2009

Social Security Administration. (2009) "Questions? How much can I earn and still receive Disability benefits?"Available at http://ssa-custhelp.ssa.gov/cgi-bin/ssa.cfg/php/enduser/std adp.php?p faqid=317. Viewed September 7, 2009

Sengupta, Ishita, Virginia Reno, and John F. Burton, Jr. (2009) "Workers' Compensation: Benefits, Coverage and Costs, 2007." Washington, DC: National Academy of Social Insurance.

Stapleton, David C. and Richard V. Burkhauser (eds.) (2003) The Decline in Employment of People with Disabilities: A Policy Puzzle. Kalamazoo, MI: W.E. Upjohn Institute for Employment Research.

Stapleton, David C., Nanette Goodman, and Andrew J. Houtenville (2003) "Have Changes in the Nature of Work or the Labor Market Reduced Employment Prospects of Workers with Disabilities?" in David C. Stapleton and Richard V. Burkhauser (eds.) The Decline in Employment of People with Disabilities: A Policy Puzzle. Kalamazoo, MI: W.E. Upjohn Institute for Employment Research.

Tanabe, Ramona P. (1998) Managed Care and Medical Cost Containment in Workers' Compensation: A National Inventory, 1998-1999. Cambridge, MA: Workers' Compensation Research Institute.

Tanabe, Ramona P. and Susan M. Murray. (2001) Managed Care and Medical Cost Containment in Workers' Compensation A National Inventory, 2001-2002. Cambridge, MA: Workers' Compensation Research Institute.

Thomason, Terry, John F. Burton, Jr., and Timothy P. Schmidle. (2001) Workers' Compensation: Benefits, Costs, and Safety under Alternative Insurance Arrangements. Kalamazoo, MI: W.E. Upjohn Institute for Employment Research.

U.S. Chamber of Commerce (2004) Analysis of Workers' Compensation Laws.

U.S. House of Representatives Committee on Ways and Means. (2004) Green Book: Overview of Entitlement Programs 2004. 
Woock,C. 2009. "Earnings Losses of Injured Men: Reported and Unreported Injuries" Industrial Relations. Volume 48 Issue 4, Pages 610 - 628 
Figure 1: Weekly Workers' Compensation Maximum Benefit Parameters, 1983 to 2006 (2000\$)

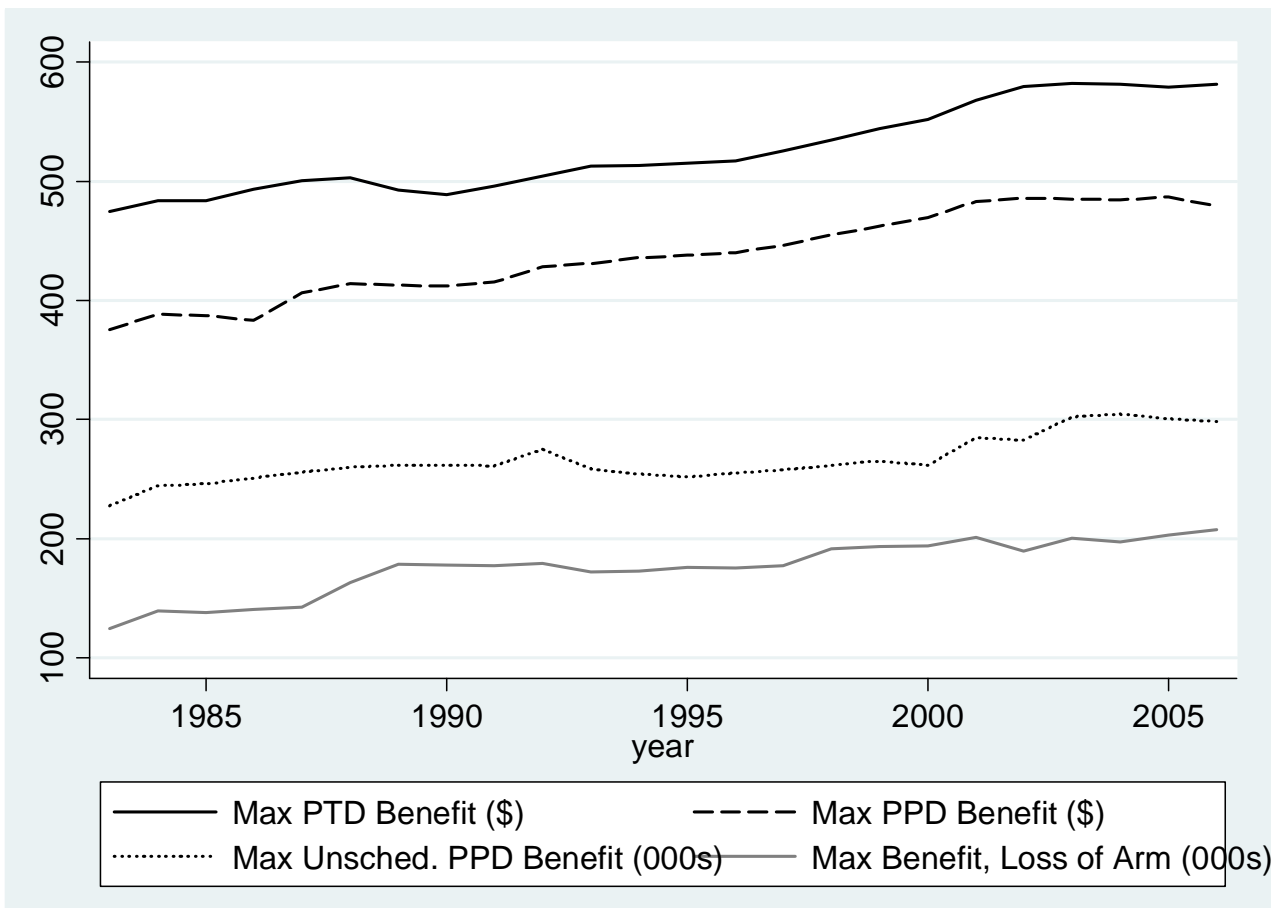

Source: Bureau of Labor Statistics. State Workers' Compensation Laws. 1983-2004. The numbers reported are means across states in a given year. These data were obtained from hard copies of the publication.

Figure 2: Workers' Compensation Maximum Duration Parameters, 1983 to 2006

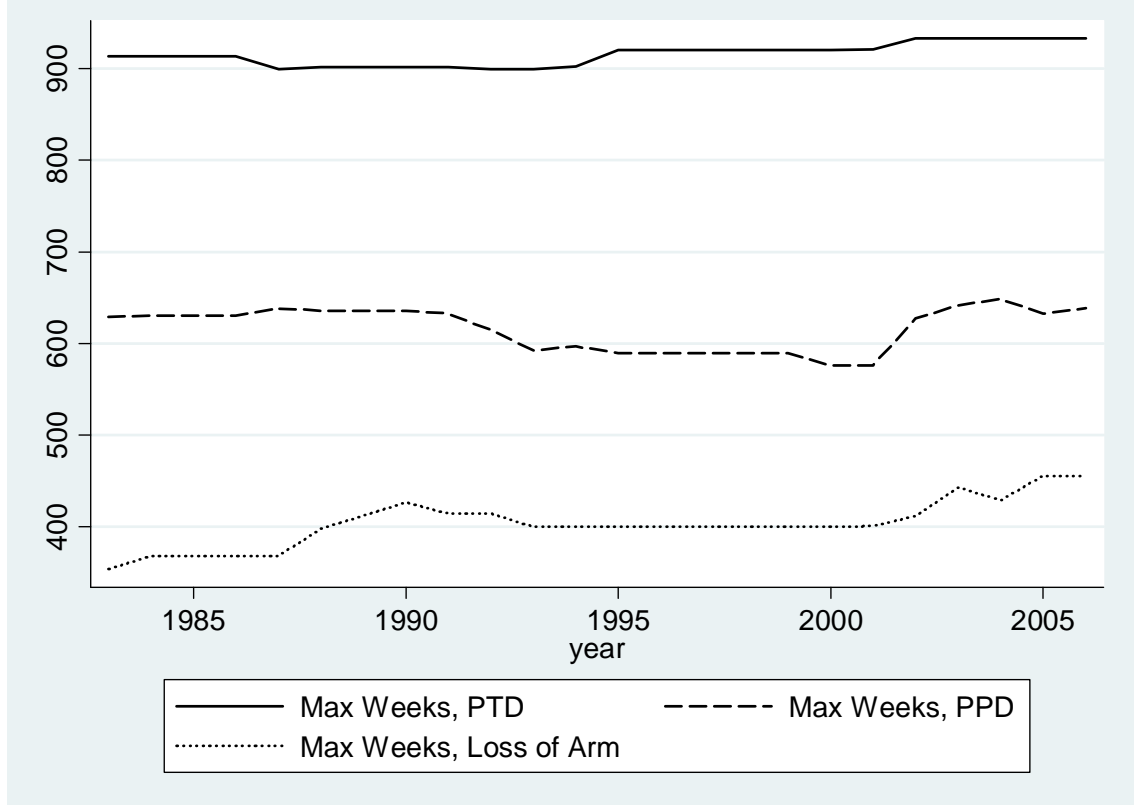

Source: Bureau of Labor Statistics. State Workers' Compensation Laws. 1983-2004. The numbers reported are means across all states in a given year. 
Figure 3: Employment Rate of Working-Age People with Disabilities, 1981 to 2008

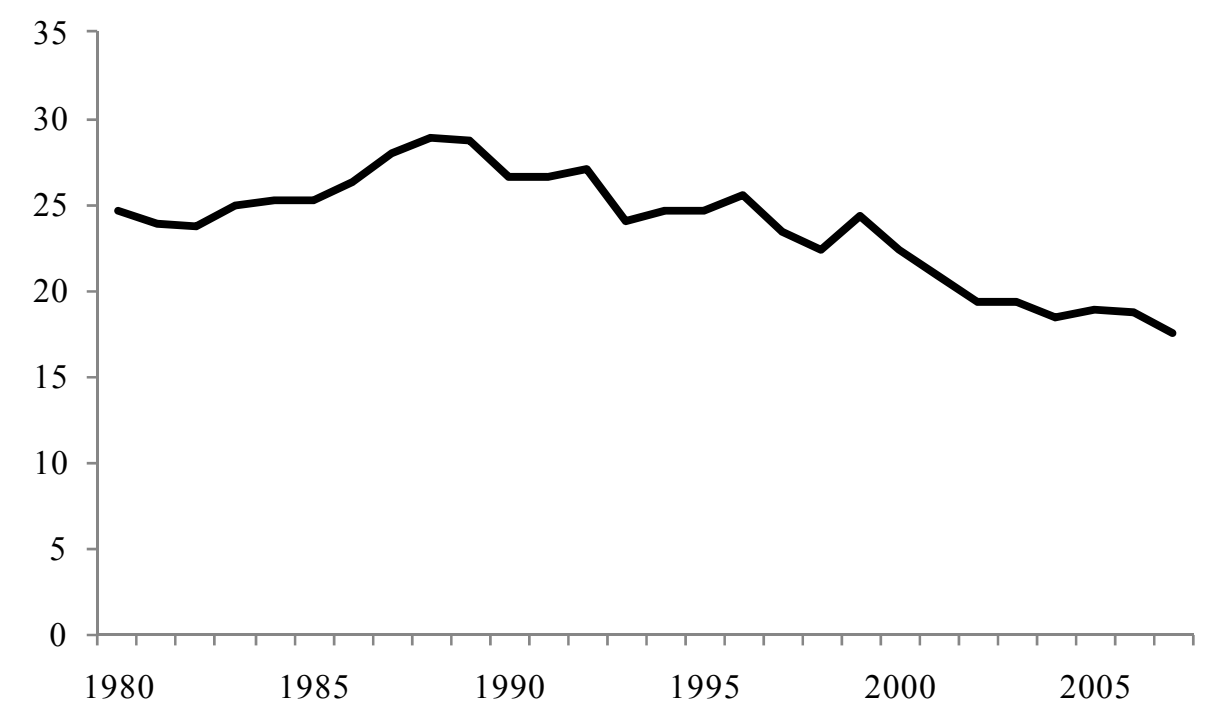

Source: Bjelland, M.J., Erickson, W.A., Lee, C.G. (2008, November 8). Disability Statistics from the Current Population Survey (CPS). Ithaca, NY: Cornell University Rehabilitation Research and Training Center on Disability Demographics and Statistics (StatsRRTC). Retrieved August 31, 2009 from www.disabilitystatistics.org.

Figure 4: Social Security Disability Insurance Outcomes, 1980 to 2006 (2000 \$)

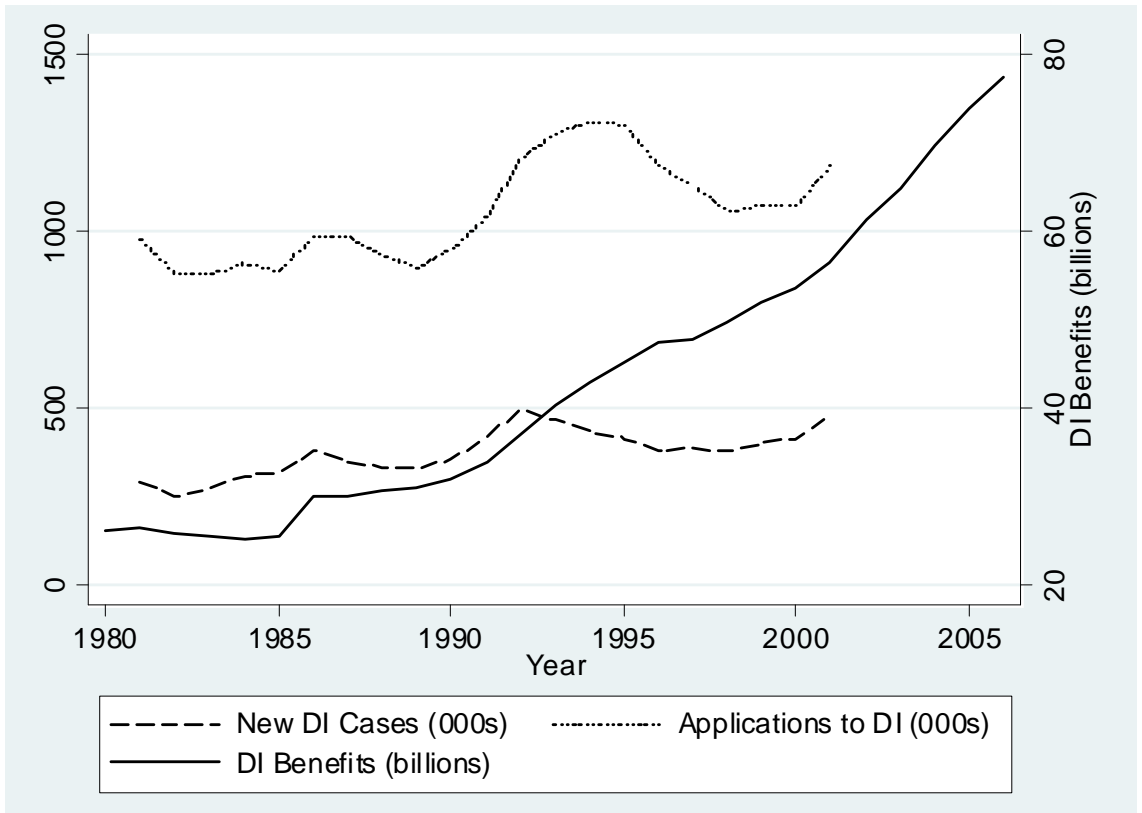

Source: Data on new DI cases and applications to DI provided by Burkhauser and Stapleton. Data on total DI benefits from Social Security Administration Annual Statistical Supplement. 
Figure 5a: Workers' Compensation Outcomes, 1980-2006

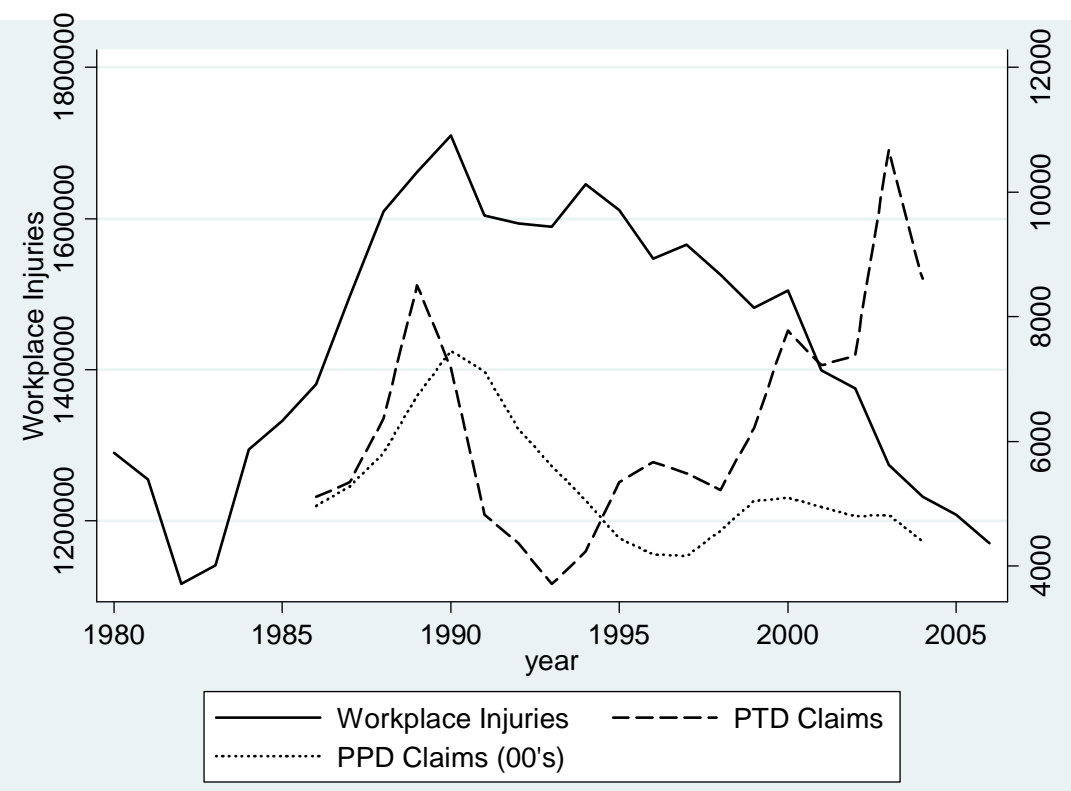

Source: Workplace Injury data from the Bureau of Labor Statistics. Permanent Partial Disability (PPD) and Permanent Total Disability (PTD) claim data from Burton and Guo.

Figure 5b: Total Workers’ Compensation Benefits (billions), 1980-2006 (2000 \$)

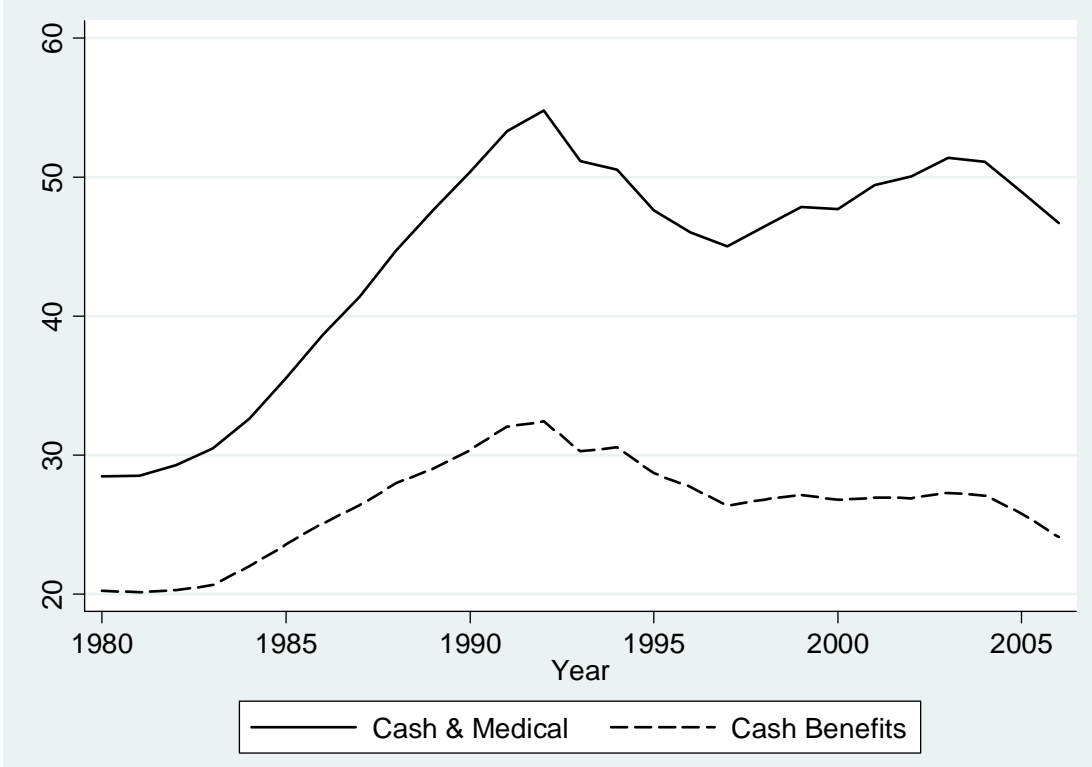

Source: Social Security Administration. 
Table 1: Quantifying Changes in Workers' Compensation Program Parameters Number of states with a change (average change in real 2000 \$ or weeks)

\begin{tabular}{|c|c|c|c|c|c|c|c|c|c|}
\hline \multirow[b]{2}{*}{ Year } & \multicolumn{2}{|c|}{ PTD Injuries } & \multicolumn{3}{|c|}{ Unscheduled PPD Injuries } & \multicolumn{2}{|c|}{ Scheduled PPD Injuries } & \multirow[b]{2}{*}{$\begin{array}{l}\text { \# States } \\
\text { Enact } \\
\text { Policy } \\
\text { Reform }\end{array}$} & \multirow[b]{2}{*}{$\begin{array}{c}\text { Average } \\
\text { Share of } \\
\text { Benefits } \\
\text { Covered by } \\
\text { Self- } \\
\text { Insurance } \\
\end{array}$} \\
\hline & $\begin{array}{c}\text { \# States } \\
\text { Decrease } \\
\text { Duration } \\
\text { PTD } \\
\text { Benefits }\end{array}$ & $\begin{array}{c}\text { \# States } \\
\text { Decrease } \\
\text { Max } \\
\text { PTD } \\
\text { Benefits }\end{array}$ & $\begin{array}{l}\text { \# States } \\
\text { Decrease } \\
\text { Duration } \\
\text { of PPD } \\
\text { Benefits }\end{array}$ & $\begin{array}{c}\text { \# States } \\
\text { Decrease } \\
\text { Max PPD } \\
\text { Benefits }\end{array}$ & $\begin{array}{l}\text { \# States } \\
\text { Decrease } \\
\text { Max PPD } \\
\text { Unsched. } \\
\text { Benefit }\end{array}$ & $\begin{array}{c}\text { \# States } \\
\text { Decrease } \\
\text { Duration of } \\
\text { Loss of Arm }\end{array}$ & $\begin{array}{c}\text { \# States } \\
\text { Decrease } \\
\text { Max Benefit } \\
\text { Loss of Arm }\end{array}$ & & \\
\hline 1984 & & $11(-21)$ & & $1(-9)$ & $14(-6,026)$ & $1(-4)$ & $2(-115)$ & -- & -- \\
\hline 1985 & & $26(0)$ & & $1(-2)$ & $28(0)$ & & $30(0)$ & -- & -- \\
\hline 1986 & & $8(-7)$ & & $1(-400)$ & $11(0)$ & & $12(0)$ & -- & -- \\
\hline 1987 & $1(-740)$ & $9(-2)$ & $1(-400)$ & $2(-8)$ & $18(-413)$ & & $15(-130)$ & -- & -- \\
\hline 1988 & & $10(-5)$ & $1(-100)$ & $3(-17)$ & $19(-2,442)$ & & $15(-474)$ & -- & -- \\
\hline 1989 & & $9(-44)$ & & & $14(0)$ & & $14(0)$ & -- & -- \\
\hline 1990 & & $6(0)$ & & & $12(0)$ & & $12(0)$ & 1 & -- \\
\hline 1991 & & $3(-6)$ & $2(-405)$ & $1(-10)$ & $11(-5,692)$ & $1(-636)$ & $10(-5,620)$ & 0 & -- \\
\hline 1992 & $1(-104)$ & $4(0)$ & $3(-323)$ & $1(-228)$ & $10(-19,379)$ & & $11(-6,573)$ & 10 & .218 \\
\hline 1993 & & $5(-15)$ & $2(-526)$ & $3(-87)$ & $11(-89,146)$ & $1(-731)$ & $11(-38,564)$ & 9 & .224 \\
\hline 1994 & $1(-150)$ & $9(-33)$ & & $1(-165)$ & $10(-59,344)$ & & $13(-3,478)$ & 7 & .254 \\
\hline 1995 & & $6(0)$ & $2(-174)$ & & $12(-17,411)$ & & $11(0)$ & 7 & .262 \\
\hline 1996 & & $10(0)$ & & $2(-12)$ & $12(0)$ & & $13(-7,492)$ & 3 & .245 \\
\hline 1997 & & $6(0)$ & & $1(-1)$ & $10(-1,160)$ & & $12(-50)$ & 2 & .244 \\
\hline 1998 & & $9(0)$ & & & $11(0)$ & & $11(0)$ & -- & .238 \\
\hline 1999 & & $9(-1)$ & & $2(-12)$ & $13(-298)$ & & $13(-136)$ & -- & .228 \\
\hline 2000 & & $6(0)$ & $1(-688)$ & & $10(-36,522)$ & $1(-20)$ & $11(-1,470)$ & -- & .221 \\
\hline 2001 & & $4(0)$ & & & $8(0)$ & & $8(0)$ & -- & .224 \\
\hline 2002 & & $10(0)$ & $1(-64)$ & $1(-491)$ & $14(-33,312)$ & $3(-314)$ & $16(-78,198)$ & -- & .225 \\
\hline 2003 & & $9(-20)$ & & $2(-84)$ & $18(-37,244)$ & & $14(-49,687)$ & -- & .228 \\
\hline 2004 & & $9(0)$ & & $1(-83)$ & $18(0)$ & $2(-360)$ & $16(-18,241)$ & -- & .239 \\
\hline 2005 & & $12(0)$ & $2(-401)$ & $1(-155)$ & $21(-14,167)$ & $1(-20)$ & $18(-2,721)$ & -- & .237 \\
\hline
\end{tabular}

Notes: Average change in parentheses (in real $2000 \$$ or weeks). PTD and PPD parameters from authors' calculations from BLS data. State policy reform data available 1990-1997, from Boden and Ruser (2003); Ruser et al. (2004); Tanabe (1998); and Tanabe and Murray (2004). Selfinsurance data available 1992-2005 from authors' calculations of National Academy of Social Insurance data (hand entered for earlier years and downloaded from the NASI website for more recent years). 
Table 2: State Level Means of Workers' Compensation Outcomes, Social Security Disability Insurance Outcomes, and Workers' Compensation Program Parameters (2000 \$)

\begin{tabular}{|c|c|c|c|}
\hline & $\begin{array}{c}\text { Mean } \\
\text { (std. dev.) }\end{array}$ & $\mathrm{N}$ & $\begin{array}{c}\text { Years } \\
\text { Available }\end{array}$ \\
\hline \multicolumn{4}{|l|}{ WC Claim Rate (per 100,000 workers) } \\
\hline Number of workplace injuries with lost workdays ${ }^{a}$ & $\begin{array}{l}2,871 \\
(817)\end{array}$ & 829 & $86-06$ \\
\hline Permanent Total Disability Cases ${ }^{\text {b }}$ & $\begin{array}{c}7.20 \\
(11.45)\end{array}$ & 907 & $85-04$ \\
\hline Permanent Partial Disability Cases ${ }^{\mathrm{b}}$ & $\begin{array}{c}560.39 \\
(302.87)\end{array}$ & 907 & $85-04$ \\
\hline \multicolumn{4}{|l|}{ WC Benefits Paid (per 100,000 workers) } \\
\hline State WC medical and cash benefits (000s) & $\begin{array}{c}41,455 \\
(19,902)\end{array}$ & 765 & $92-06$ \\
\hline State WC cash benefits $(000 \mathrm{~s})$ & $\begin{array}{c}20,809 \\
(12,628)\end{array}$ & 561 & $96-06$ \\
\hline \multicolumn{4}{|l|}{ DI Claim Rate (per 100,000 workers) } \\
\hline Applications to DI & $\begin{array}{l}1,182 \\
(417)\end{array}$ & 816 & $86-01$ \\
\hline New DI cases & $\begin{array}{c}433 \\
(112) \\
\end{array}$ & 816 & $86-01$ \\
\hline \multicolumn{4}{|l|}{ DI Benefits Paid (per 100,000 workers) } \\
\hline State DI Benefits (000s) & $\begin{array}{c}48,899 \\
(20,992)\end{array}$ & 1,071 & $86-06$ \\
\hline \multicolumn{4}{|l|}{ PTD Program Parameters } \\
\hline Maximum Weekly PTD Benefit & $\begin{array}{c}525.31 \\
(179.12)\end{array}$ & 1,224 & $83-06$ \\
\hline Max Duration PTD (in Weeks) & $\begin{array}{c}915.55 \\
(206.41)\end{array}$ & 1,224 & $83-06$ \\
\hline \multicolumn{4}{|l|}{ PPD Program Parameters } \\
\hline PPD Maximum Weekly Benefit ${ }^{\mathrm{c}}$ & $\begin{array}{c}437.84 \\
(177.55)\end{array}$ & 1,176 & $83-06$ \\
\hline Max Duration PPD Benefits (in Weeks) ${ }^{\mathrm{d}}$ & $\begin{array}{c}616.23 \\
(298.17)\end{array}$ & 1,152 & $83-06$ \\
\hline Total PPD Benefits, Unscheduled Injuries & $\begin{array}{c}266,122 \\
(205,976)\end{array}$ & 1,224 & $83-06$ \\
\hline Weeks of Benefits, Loss of Arm & $\begin{array}{c}403.40 \\
(308.28)\end{array}$ & 1,224 & $83-06$ \\
\hline Dollar Value, Loss of an Arm & $\begin{array}{c}175,675 \\
(175,995)\end{array}$ & 1,224 & $83-06$ \\
\hline \multicolumn{4}{|l|}{ Policy Changes in the 1990 s } \\
\hline$=1$ if Objective Medical Evidence Required & .11 & 408 & $90-97$ \\
\hline$=1$ if Nonwork impacts ruled out & .07 & 408 & $90-97$ \\
\hline$=1$ if Employer Chooses Doctor & .27 & 612 & $90-01$ \\
\hline$=1$ if Penalties for Fraudulent Claims & .21 & 408 & $90-97$ \\
\hline Share of Benefits covered by Self-insuring employers & .23 & 764 & 92-06 \\
\hline
\end{tabular}

The average state has two million workers.

${ }^{a}$ Exclude states that do not report injury data to Bureau of Labor Statistics.

${ }^{\mathrm{b}}$ Exclude states that do not use National Council on Compensation Insurance to set premium rates.

${ }^{\mathrm{c} E x c l u d e}$ Alaska and Washington because have lump sum PPD benefits and do not list maximum weeks.

${ }^{\mathrm{d}}$ Exclude Alaska, Washington, Indiana because have lump sum PPD benefits and do not list maximum duration.

Table 3: The Relationship Between Security Disability Insurance Outcomes and Workers' Compensation Outcomes

DI New DI Cases $\quad$ Real DI




\begin{tabular}{|c|c|c|c|}
\hline & $\begin{array}{c}\text { Applications } \\
\text { per } 100,000 \\
\text { Workers }\end{array}$ & $\begin{array}{l}\text { per } 100,000 \\
\text { Workers }\end{array}$ & $\begin{array}{c}\text { Spending per } \\
100,000 \\
\text { Workers }(000 \mathrm{~s})\end{array}$ \\
\hline \multicolumn{4}{|c|}{ Panel 1: With State and Year Effects } \\
\hline Number of Workplace Injuries per 100,000 & $-.110 * *$ & $-.062 * *$ & $-3.440 *$ \\
\hline Workers & $(.039)$ & $(.013)$ & $(1.732)$ \\
\hline \multirow[t]{2}{*}{ Permanent Total Cases per 100,000 Workers } & .117 & -.259 & -4.870 \\
\hline & $(.425)$ & $(.267)$ & $(28.604)$ \\
\hline \multirow[t]{2}{*}{ Permanent Partial Cases per 100,000 Workers } & -.041 & -.047 & -2.653 \\
\hline & $(.076)$ & $(.032)$ & $(2.595)$ \\
\hline Real WC Spending per 100,000 Workers & .001 & .0001 & .043 \\
\hline$(000 \mathrm{~s})$ & $(.001)$ & $(.0005)$ & $(.059)$ \\
\hline Real WC Cash Benefit Spending per 100,000 & $.003 * *$ & .0005 & -.112 \\
\hline Workers $(000 \mathrm{~s})$ & $(.001)$ & $(.0013)$ & $(.160)$ \\
\hline \multicolumn{4}{|c|}{ Panel 2: With All Covariates } \\
\hline Number of Workplace Injuries per 100,000 & -.004 & $-.044 * *$ & $-4.997 * *$ \\
\hline Workers & $(.036)$ & $(.013)$ & $(1.678)$ \\
\hline \multirow[t]{2}{*}{ Permanent Total Cases per 100,000 Workers } & -.036 & -.219 & -13.788 \\
\hline & $(.486)$ & $(.174)$ & $(18.747)$ \\
\hline \multirow{2}{*}{ Permanent Partial Cases per 100,000 Workers } & .040 & -.019 & -2.588 \\
\hline & $(.044)$ & $(.022)$ & $(2.281)$ \\
\hline Real WC Spending per 100,000 Workers & .0006 & .00003 & .015 \\
\hline$(000 \mathrm{~s})$ & $(.0009)$ & $(.00048)$ & $(.044)$ \\
\hline Real WC Cash Benefit Spending per 100,000 & $.003 * *$ & .0009 & -.126 \\
\hline Workers (000s) & $(.001)$ & $(.0012)$ & $(.125)$ \\
\hline Mean of Dependent Variable & $\begin{array}{l}1,182 \\
(417)\end{array}$ & $\begin{array}{c}433 \\
(112)\end{array}$ & $\begin{array}{c}48,899 \\
(20,992)\end{array}$ \\
\hline
\end{tabular}

Each cell contains a coefficient estimate and standard error for the independent variable of interest from a separate regression where the dependent variable is the column heading, and the independent variable of interest is the row heading. Each regression includes an intercept. All dollars are in year 2000 terms. The full set of covariates in Panel C includes: the state unemployment rate; the share of the state population ages 45-54 and the share of the state population ages 55-64; the share of workers in the following industries (agriculture, mining, construction, manufacturing-durable goods, manufacturing-nondurable goods, transportation, wholesale, retail trade, finance, insurance, and real estate, business and repair services, personal services, and professional services is the left out category), the number of workers ages 25-64 (in millions) as well as state and year fixed effects. Standard errors are clustered by state. 
Table 4: The Effect of Workers' Compensation Program Parameters on Workers' Compensation Outcomes

\begin{tabular}{cccccc}
\hline Dependent Variable: & Work & PTD & PPD Cases & All WC & WC Cash \\
& Injuries & Cases (per & (per & Benefit & Benefit \\
& (per & 100,000 & 100,000 & Spending & Spending \\
100,000 & workers) & workers) & per 100,000 & per \\
& workers) & & & workers & 100,000 \\
& & & & $(000 \mathrm{~s})$ & workers
\end{tabular}

\begin{tabular}{|c|c|c|c|c|c|}
\hline & & & & & \\
\hline Independent Variable: & $(1)$ & $(2)$ & $(3)$ & $(4)$ & $(5)$ \\
\hline \multicolumn{6}{|c|}{ Panel A: Measures of WC Generosity, Considered Independently } \\
\hline Max PTD Weekly Benefit & $\begin{array}{l}.457 * * \\
(.251)\end{array}$ & $\begin{array}{l}.000009 \\
(.00903)\end{array}$ & $\begin{array}{l}.057 \\
(.140)\end{array}$ & $\begin{array}{l}27.040 \\
(22.873)\end{array}$ & $\begin{array}{c}17.219 \\
(11.203)\end{array}$ \\
\hline Max Duration PTD (weeks) & $\begin{array}{l}.128 \\
(.182)\end{array}$ & $\begin{array}{l}-.019 \\
(.024)\end{array}$ & $\begin{array}{l}-.047 \\
(.119)\end{array}$ & $\begin{array}{l}-2.359 \\
(5.969)\end{array}$ & $\begin{array}{l}7.347^{* *} \\
(1.750)\end{array}$ \\
\hline PPD Max Weekly Benefit & $\begin{array}{l}.544 \\
(.507)\end{array}$ & $\begin{array}{l}.014 \\
(.011)\end{array}$ & $\begin{array}{l}.434 * * \\
(.144)\end{array}$ & $\begin{array}{l}32.451^{*} \\
(17.400)\end{array}$ & $\begin{array}{c}20.276^{* *} \\
(7.775)\end{array}$ \\
\hline Max Duration PPD Benefits (weeks) & $\begin{array}{l}.180 \\
(.267)\end{array}$ & $\begin{array}{l}.0009 \\
(.0034)\end{array}$ & $\begin{array}{l}-.015 \\
(.092)\end{array}$ & $\begin{array}{c}4.444 \\
(3.472)\end{array}$ & $\begin{array}{c}-4.467 * * \\
(1.951)\end{array}$ \\
\hline $\begin{array}{l}\text { Total PPD Benefits, Unscheduled Injuries } \\
\text { (in thousands) }\end{array}$ & $\begin{array}{l}.081 \\
(.343)\end{array}$ & $\begin{array}{l}.003 \\
(.005)\end{array}$ & $\begin{array}{l}.086 \\
(.136)\end{array}$ & $\begin{array}{l}14.316^{* *} \\
(7.213)\end{array}$ & $\begin{array}{l}.331 \\
(4.456)\end{array}$ \\
\hline Weeks of Benefits, Loss of an Arm & $\begin{array}{l}.265 * * \\
(.115)\end{array}$ & $\begin{array}{l}.012^{* *} \\
(.005)\end{array}$ & $\begin{array}{c}.040 \\
(.058)\end{array}$ & $\begin{array}{c}1.887 \\
(6.107)\end{array}$ & $\begin{array}{c}2.755 \\
(3.339)\end{array}$ \\
\hline $\begin{array}{l}\text { Dollar Value, Loss of an Arm (in } \\
\text { thousands) }\end{array}$ & $\begin{array}{l}.211 \\
(.193)\end{array}$ & $\begin{array}{l}.012 \\
(.008)\end{array}$ & $\begin{array}{l}.053 \\
(.083)\end{array}$ & $\begin{array}{c}4.062 \\
(7.435) \\
\end{array}$ & $\begin{array}{c}2.135 \\
(4.170)\end{array}$ \\
\hline$=1$ if No Max for PPD Benefits & $\begin{array}{c}173.206 \\
(148.433) \\
\end{array}$ & $\begin{array}{c}2.579 \\
(1.736) \\
\end{array}$ & $\begin{array}{c}49.302 \\
(57.005) \\
\end{array}$ & $\begin{array}{l}5,902 * * \\
(1.990) \\
\end{array}$ & $\begin{array}{l}-3,385^{*} \\
(1,824) \\
\end{array}$ \\
\hline \multicolumn{6}{|c|}{ Panel B: Measures of WC Generosity, Considered Together } \\
\hline Max PTD Wkly Benefit & $\begin{array}{l}.562 * * \\
(.189)\end{array}$ & $\begin{array}{l}.004 \\
(.007)\end{array}$ & $\begin{array}{l}.047 \\
(.113)\end{array}$ & $\begin{array}{c}22.460 \\
(21.658)\end{array}$ & $\begin{array}{c}18.052 \\
(11.057)\end{array}$ \\
\hline $\begin{array}{l}\text { Total PPD Benefits (Unscheduled Injuries) } \\
\text { (in thousands) }\end{array}$ & $\begin{array}{l}-.194 \\
(.262)\end{array}$ & $\begin{array}{l}-.004 \\
(.004)\end{array}$ & $\begin{array}{l}.065 \\
(.132)\end{array}$ & $\begin{array}{c}12.896^{* *} \\
(5.686)\end{array}$ & $\begin{array}{l}-1.993 \\
(4.635)\end{array}$ \\
\hline Weeks of Benefits, Lose Arm & $\begin{array}{l}.324 * * \\
(.086)\end{array}$ & $\begin{array}{l}.014 * * \\
(.006)\end{array}$ & $\begin{array}{r}.027 \\
(.068)\end{array}$ & $\begin{array}{l}-.739 \\
(4.637)\end{array}$ & $\begin{array}{c}3.142 \\
(3.136)\end{array}$ \\
\hline \multicolumn{6}{|c|}{ Panel C: Measures of WC System Changes, Considered Independently } \\
\hline $\begin{array}{l}=1 \text { if Objective Medical Evidence } \\
\text { Required }\end{array}$ & $\begin{array}{c}75.256 \\
(103.407)\end{array}$ & $\begin{array}{l}-1.663 \\
(3.711)\end{array}$ & $\begin{array}{l}-80.418 \\
(68.514)\end{array}$ & $\begin{array}{l}-2,507 \\
(3,195)\end{array}$ & $\begin{array}{c}472 \\
(14,506)\end{array}$ \\
\hline$=1$ if Nonwork Impacts Ruled Out & $\begin{array}{c}-192.173 * * \\
(79.980)\end{array}$ & $\begin{array}{l}1.002 \\
(2.625)\end{array}$ & $\begin{array}{l}-77.054 \\
(82.751)\end{array}$ & $\begin{array}{l}-3,055 \\
(8,924)\end{array}$ & $\begin{array}{c}3,984 \\
(15,688)\end{array}$ \\
\hline$=1$ if Employer Chooses Doctor & $\begin{array}{l}-49.993 \\
(58.282)\end{array}$ & $\begin{array}{l}-1.338 \\
(1.351)\end{array}$ & $\begin{array}{l}-31.524 \\
(35.002)\end{array}$ & $\begin{array}{r}-3.937 \\
(2,756)\end{array}$ & $\begin{array}{l}2,083^{*} \\
(1,202)\end{array}$ \\
\hline$=1$ if Penalties for Fraudulent Claims & $\begin{array}{c}47.591 \\
(64.292)\end{array}$ & $\begin{array}{l}-3.566^{*} \\
(2.068)\end{array}$ & $\begin{array}{l}-82.515 \\
(58.393)\end{array}$ & $\begin{array}{c}347 \\
(3,696)\end{array}$ & $\begin{array}{c}-472 \\
(14,506)\end{array}$ \\
\hline$=1$ if Any of the Above Policies & $\begin{array}{c}-45.641 \\
(58.576)\end{array}$ & $\begin{array}{c}-.102 \\
(1.447)\end{array}$ & $\begin{array}{c}-55.186 \\
(39.880)\end{array}$ & $\begin{array}{c}-2,997 \\
(4,103)\end{array}$ & $\begin{array}{c}1,941 \\
(23,041)\end{array}$ \\
\hline Share benefits self-insured & $\begin{array}{c}-87.897 \\
(245.873)\end{array}$ & $\begin{array}{c}4.029 \\
(4.394)\end{array}$ & $\begin{array}{l}-148.600 \\
(125.940)\end{array}$ & $\begin{array}{c}-2,517 \\
(15,681)\end{array}$ & $\begin{array}{c}7,349 \\
(7,302)\end{array}$ \\
\hline Mean of Dependent Variable & $\begin{array}{l}2,871 \\
(817)\end{array}$ & $\begin{array}{c}7.20 \\
(11.45)\end{array}$ & $\begin{array}{c}560.39 \\
(302.87)\end{array}$ & $\begin{array}{c}41,455 \\
(19,902)\end{array}$ & $\begin{array}{c}20,809 \\
(12,628)\end{array}$ \\
\hline
\end{tabular}

Each cell contains a coefficient estimate and standard error for the independent variable of interest from a separate regression, in the case of Panels A and C. In Panel B, all the independent variables are entered together into the same regression (one regression for each column heading). Each regression includes an intercept. All dollars are in $2000 \$$. Standard errors are clustered by state. See notes to Table 3 for listing of full set of covariates. 
Table 5: The Effect of Workers' Compensation Program Parameters on Social Security Disability Insurance Outcomes

\begin{tabular}{|c|c|c|c|}
\hline Dependent Variable: & $\begin{array}{c}\text { DI Applications } \\
\text { (per } 100,000 \\
\text { workers) }\end{array}$ & $\begin{array}{l}\text { New DI Cases (per } \\
100,000 \text { workers) }\end{array}$ & $\begin{array}{c}\text { Real DI Spending } \\
(2000 \$) \text { per } \\
100,000 \text { workers } \\
(000 \mathrm{~s})\end{array}$ \\
\hline Independent Variable: & $(1)$ & $(2)$ & (3) \\
\hline \multicolumn{4}{|c|}{ Panel A: Measures of WC Generosity, Considered Independently } \\
\hline Max PTD Weekly Benefit & $\begin{array}{l}-.153 * * \\
(.060)\end{array}$ & $\begin{array}{l}-.104 * * \\
(.029)\end{array}$ & $\begin{array}{l}-8.653 \\
(5.285)\end{array}$ \\
\hline Max Duration PTD (weeks) & $\begin{array}{l}-.080 \\
(.083)\end{array}$ & $\begin{array}{l}-.033 \\
(.021)\end{array}$ & $\begin{array}{l}3.923 * \\
(2.056)\end{array}$ \\
\hline PPD Max Weekly Benefit & $\begin{array}{l}-.070 \\
(.086)\end{array}$ & $\begin{array}{l}-.081 \\
(.054)\end{array}$ & $\begin{array}{l}-7.619 \\
(7.069)\end{array}$ \\
\hline Max Duration PPD Benefits (weeks) & $\begin{array}{r}-.074 * \\
(.043)\end{array}$ & $\begin{array}{l}-.003 \\
(.031)\end{array}$ & $\begin{array}{l}-3.090 \\
(3.877)\end{array}$ \\
\hline $\begin{array}{l}\text { Total PPD Benefits, Unscheduled } \\
\text { Injuries (in thousands) }\end{array}$ & $\begin{array}{l}-.134 * \\
(.070)\end{array}$ & $\begin{array}{l}-.064 \\
(.044)\end{array}$ & $\begin{array}{l}-5.458 \\
(6.498)\end{array}$ \\
\hline Weeks of Benefits, Loss of an Arm & $\begin{array}{l}-.052 \\
(.040)\end{array}$ & $\begin{array}{l}-.012 \\
(.026)\end{array}$ & $\begin{array}{l}-7.699 * * \\
(3.862)\end{array}$ \\
\hline $\begin{array}{l}\text { Dollar Value, Loss of an Arm (in } \\
\text { thousands) }\end{array}$ & $\begin{array}{l}-.031 \\
(.041)\end{array}$ & $\begin{array}{l}-.000004 \\
(.029979)\end{array}$ & $\begin{array}{l}-8.792 \\
(5.643)\end{array}$ \\
\hline$=1$ if No Max for PPD Benefits & $\begin{array}{l}-27.163 \\
(29.833)\end{array}$ & $\begin{array}{c}-3.085 \\
(19.569)\end{array}$ & $\begin{array}{l}-1,611 \\
(3,148)\end{array}$ \\
\hline \multicolumn{4}{|c|}{ Panel B: Measures of WC Generosity, Considered Together } \\
\hline Max PTD Wkly Benefit & $\begin{array}{l}-.138^{*} \\
(.078)\end{array}$ & $\begin{array}{c}-.096 * * \\
(.039)\end{array}$ & $\begin{array}{c}-9.298 * * \\
(4.649)\end{array}$ \\
\hline $\begin{array}{l}\text { Total PPD Benefits (Unscheduled } \\
\text { Injuries) (in millions) }\end{array}$ & $\begin{array}{l}-.090 \\
(.074)\end{array}$ & $\begin{array}{l}-.040 \\
(.052)\end{array}$ & $\begin{array}{c}-.661 \\
(7.097)\end{array}$ \\
\hline Weeks of Benefits, Lose Arm & $\begin{array}{l}-.046 \\
(.045)\end{array}$ & $\begin{array}{l}-.013 \\
(.025)\end{array}$ & $\begin{array}{l}-7.797 \\
(4.814)\end{array}$ \\
\hline \multicolumn{4}{|c|}{ Panel C: Measures of WC System Changes, Considered Independently } \\
\hline $\begin{array}{c}=1 \text { if Objective Medical Evidence } \\
\text { Required }\end{array}$ & $\begin{array}{c}6.942 \\
(43.920)\end{array}$ & $\begin{array}{c}1.567 \\
(17.466)\end{array}$ & $\begin{array}{c}-75 \\
(1,177)\end{array}$ \\
\hline$=1$ if Nonwork Impacts Ruled Out & $\begin{array}{c}14.891 \\
(27.132)\end{array}$ & $\begin{array}{c}-7.101 \\
(14.318)\end{array}$ & $\begin{array}{c}1,105 \\
(1,444)\end{array}$ \\
\hline$=1$ if Employer Chooses Doctor & $\begin{array}{c}-7.582 \\
(20.316)\end{array}$ & $\begin{array}{l}-12.859 \\
(13.073)\end{array}$ & $\begin{array}{l}1,021 \\
(885)\end{array}$ \\
\hline$=1$ if Penalties for Fraudulent Claims & $\begin{array}{c}9.257 \\
(25.392)\end{array}$ & $\begin{array}{l}-3.843 \\
(9.836)\end{array}$ & $\begin{array}{l}1,084 \\
(893)\end{array}$ \\
\hline$=1$ if Any of the Above Policies & $\begin{array}{c}7.011 \\
(20.099)\end{array}$ & $\begin{array}{l}-4.028 \\
(9.220)\end{array}$ & $\begin{array}{l}1,242^{*} \\
(680)\end{array}$ \\
\hline Share benefits self-insured & $\begin{array}{l}-158.408 \\
(113.214)\end{array}$ & $\begin{array}{c}-179.007 * * \\
(65.527)\end{array}$ & $\begin{array}{c}-72 \\
(6,064)\end{array}$ \\
\hline Mean of Dependent Variable & $\begin{array}{l}1,182 \\
(417)\end{array}$ & $\begin{array}{c}433 \\
(112) \\
\end{array}$ & $\begin{array}{c}48,899 \\
(20,992)\end{array}$ \\
\hline
\end{tabular}

See notes to Table 4 for explanation. 


\section{Data on Workers' Compensation Outcomes}

Workplace Injuries per 100,000 workers

This series is constructed from three state level Bureau of Labor Statistics data sources. From 1981 to 1998, we used data on "Lost Workday Cases" from the series "Number of nonfatal occupational injuries and illnesses by State, private industry." Data through 1998 were provided to us in hard copy upon request directly from BLS, and were hand entered by us into electronic format. Data from 1996 onward are available electronically on the BLS website as a series of separate Adobe documents. ${ }^{51}$ Between 1998 and 2001, we used the series "Lost workday cases" from "Number of nonfatal occupational injuries and illnesses by industry and selected case types." Between 2002 and 2006, we used "Total Cases with days away from work, job transfer, or restriction (Private Industry)" from the series, "Numbers of nonfatal occupational injuries and illnesses by industry and case types." These BLS data are presented in thousands and are available in states reporting injury statistics to BLS for the years 1981 through 2007. To get the number of workplace injuries per 100,000 workers, we use data on total employment from the U.S. Census Bureau's County Business Patterns (CBP) series. We use the series, "Paid employees for pay period including March 12.,"52

Workplace Injuries Per $100 k$ Workers $=\frac{\# \text { Lost Workdays } * 1,000}{\text { CBP Total Employment }} \times 100,000$

Permanent Total Disability Cases per 100,000 Workers and Permanent Partial Disability Cases per 100,000 Workers Data on the frequency of WC receipt (PPD and PTD claims per 100,000 workers) were coded from documents generously provided by John Burton and Steve Guo. Data for the years 2003 and 2004 can be found in the publication, Workers' Compensation Policy Review. ${ }^{53}$ Data on these two series are available for all states which have premiums rated by the National Council on Compensation Insurance for the years 1985 to 2004. The data series also includes information for a few states and years not rated by the National Council on Compensation Insurance (i.e., Delaware, Pennsylvania, and West Virginia). ${ }^{54}$ Note that with the exception of West Virginia (an exclusive state fund), these data series only represent the frequency of WC claims files with competitive, private insurers. Claims filed with self-insuring employers or state funds are not included in these totals.

State WC Medical and Cash Benefits (000s) per 100,000 workers and State WC Cash Benefits (000s) per 100,000 workers Data on WC program spending are available through the National Academy of Social Insurance annual publication Workers' Compensation: Benefits, Coverage, and Costs. ${ }^{55}$ Data are presented in thousands and available by state from 1992 through 2006 for medical and cash benefits combined. Data on cash benefits by state are only available from 1996 through 2006. To get these series per 100,000 workers, we use the CBP data described above.

$$
\text { WC Benefit Per 100k Workers }(000 s)=\frac{\text { Total WC Benefit Spending }(000 s)}{\text { CBP Total Employment }} \times 100,000
$$

\section{$\underline{\text { Data on DI Outcomes }}$}

Applications to DI per 100,000 workers and new DI cases per 100,000 workers

State totals on the number of new applications to DI and the number of new DI cases by state and year were generously provided by Richard Burkhauser and Dave Stapleton. Data on applications and new cases are available from 1980 to 2001

\footnotetext{
${ }^{51}$ These data are available online at http://www.bls.gov/iif/oshstate.htm\#AL for the years 1996 through 2007. Last viewed September $9,2009$.

${ }_{52}$ These data are available online at http://censtats.census.gov/cbpsic/cbpsic.shtml for years 1986 through 1997 (last viewed September 9, 2009) and at http://www.census.gov/econ/cbp/index.html for 1998 through 2007 (last viewed September 9, 2009).

${ }^{53}$ Data for 2003 are available in the September/October 2007 edition of the Workers' Compensation Policy Review (Vol. 7, Issue 5), and data for 2004 are available in the July/August 2008 edition of the Workers' Compensation Policy Review (Vol. 8, Issue 4).

${ }^{54}$ Data are missing for Nevada prior to 1996 and for Delaware, Pennsylvania, Texas, and West Virginia in certain years.

${ }^{55}$ This publication is at http://www.nasi.org/search_site2710/search_site_results.htm (last viewed September 9, 2009).
} 
for all states. We obtain the total number of applications by summing the number of initial applications to the DI program (initDItotal) and the number of initial applications to the DI and SSI programs (initcontotal). The total number of new cases is the sum the number of initial DI only allowances (initDIallow) and the number of initial DI and SSI allowances (initconallow). To get these series per 100,000 workers, we use the CBP data described above.

$$
\text { DI Applications or New Cases per 100k Workers }=\frac{\text { Total Applications or Cases }}{\text { CBP Total Employment }} \times 100,000
$$

State DI Benefits (000s) per 100,000 workers

Data on total DI benefits paid in each state, in each year, are published in the Social Security Bulletin's Annual Statistical Supplement. Data are available in each state for the years 1980 to 2006 and presented in millions. ${ }^{56}$ To get this series per 100,000 workers, we use the CBP data described above.

$$
\text { DI Benefits Paid per } 100 k \text { Workers }(000 s)=\frac{\text { Total DI Benefits } * 1,000}{C B P \text { Total Employment }} \times 100,000
$$

\section{Data on WC Program Parameters}

\section{PTD Program Parameters and PPD Program Parameters}

Data on PTD and PPD program parameters were entered from hard copy and microfiche editions of the BLS annual publication, State Workers' Compensation Laws. Annual data are available in all states from 1983 to 2006. In this paper, we examine the following parameters: maximum weekly PTD benefit; maximum PTD duration (in weeks); maximum weekly PPD benefit; maximum PPD duration (in weeks); maximum PPD benefits allowed for unscheduled injuries; maximum weeks of benefits for a scheduled injury (loss of an arm); and maximum PPD benefits allowed for a scheduled injury (loss of an arm).

\section{Policy Changes in the 1990s}

The data on policy changes at the annual level in the 1990s are taken from Boden and Ruser (2003) and Ruser et al. (2004). These papers present the policy changes occurring between 1990 and 1997 . These papers quantify four types of WC policy changes: states that rule out injuries if no objective medical evidence is available; states that rule out injuries if the workplace injury only contributed to the disability; states that allow the employer — not the employee- to choose the treating doctor; and states that enact stiff penalties for fraudulent claims. We were able to extend one of these series, does the employer choose the doctor, using the Workers' Compensation Research Institute publication, "Managed Care and Medical Cost Containment in Workers' Compensation A National Inventory” for 1998-1999 and 2001-2002.

\section{Share of Benefits Covered by Self-Insurance}

These data are available by state by year in the National Academy of Social Insurance annual publication Workers' Compensation: Benefits, Costs, and Coverage. These data are available from 1992 through $2006 .{ }^{57}$

\footnotetext{
${ }^{56}$ We obtained hard copies of the publication for the years 1980 through 2001. Data from 2002 through 2006 are available online at http://www.socialsecurity.gov/policy/docs/statcomps/supplement/2008/index.html. (Last viewed September 9, 2009).

${ }^{57}$ This publication is available at http://www.nasi.org/search_site2710/search_site_results.htm. (Last viewed September 9, 2009.)
} 
Appendix 2: Scatterplots of the Relationship Between State Level Annual Changes in Security Disability Insurance Outcomes vs State Level Annual Changes in Workers' Compensation Outcomes

Key to Graphs

$\begin{array}{ccc}\text { DI Applications per } & \text { New DI Cases per } & \text { Real DI Spending per } \\ 100,000 \text { Workers } & 100,000 \text { Workers } & 100,000 \text { Workers } \\ & & (000 \mathrm{~s})\end{array}$

(dy_app100w)

(dy_new100w)

(dy_did100w)

\begin{tabular}{|c|c|c|c|}
\hline $\begin{array}{l}\text { Number of Workplace Injuries per 100,000 Workers } \\
\left(\mathrm{dx} \_ \text {inj100w) }\right.\end{array}$ & $\# 1$ & 6 & 11 \\
\hline Permanent Total Cases per 100,000 Workers (dx_pt_f $)$ & 2 & 7 & 12 \\
\hline Permanent Partial Cases per 100,000 Workers (dx_ppd_f) & 3 & 8 & 13 \\
\hline Real WC Spending per 100,000 Workers $(000 s)\left(d x \_w c d 100 w\right)$ & 4 & 9 & 14 \\
\hline $\begin{array}{l}\text { Real WC Cash Benefit Spending per } 100,000 \text { Workers }(000 \text { s) } \\
(\mathrm{dx} \text { wcc } 100 w)\end{array}$ & 5 & 10 & 15 \\
\hline
\end{tabular}

Note: Each data point represents a state year pair of data. Observations are not included unless both $\mathrm{x}$ and $\mathrm{y}$ coordinates are non-missing.
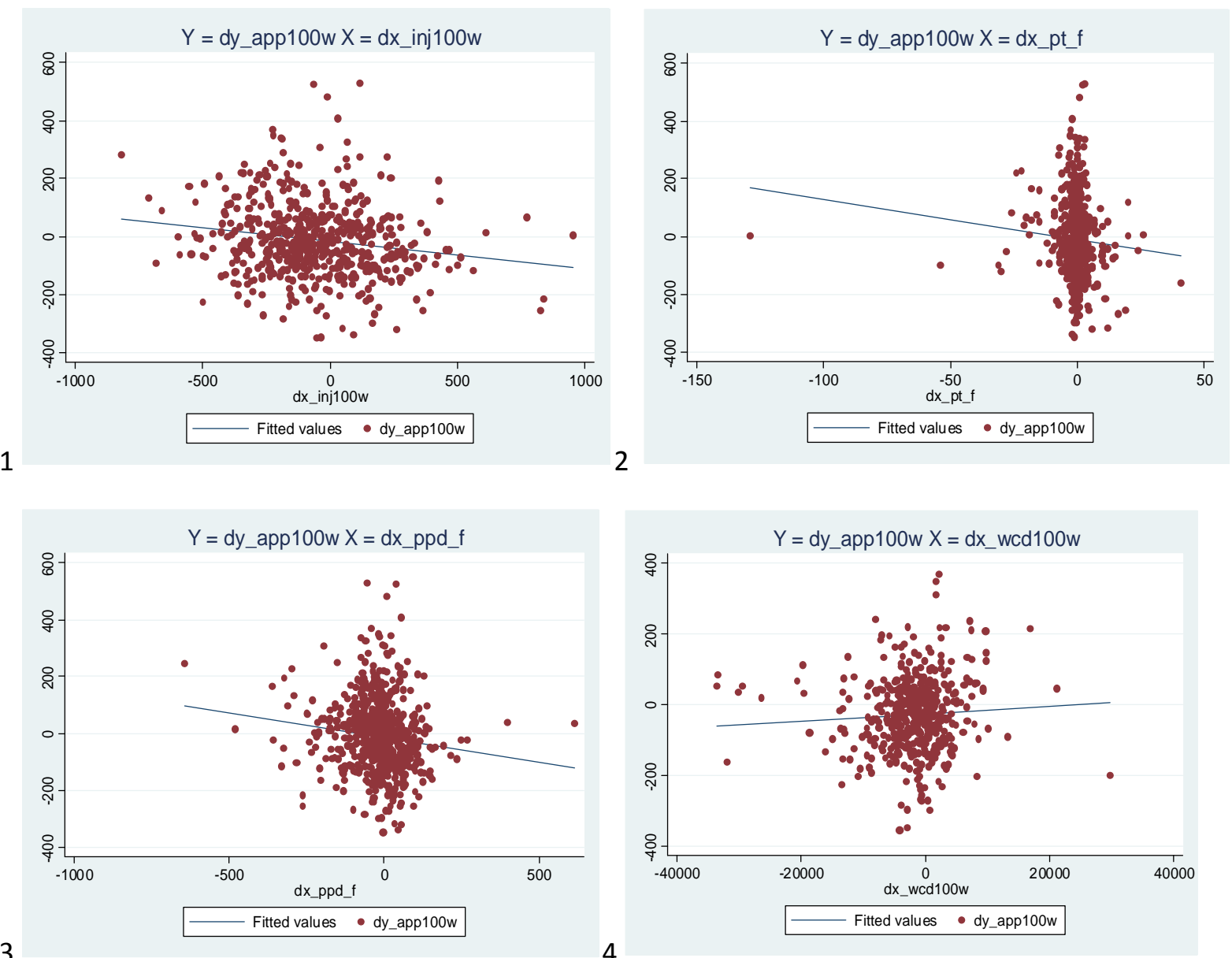

3

4 

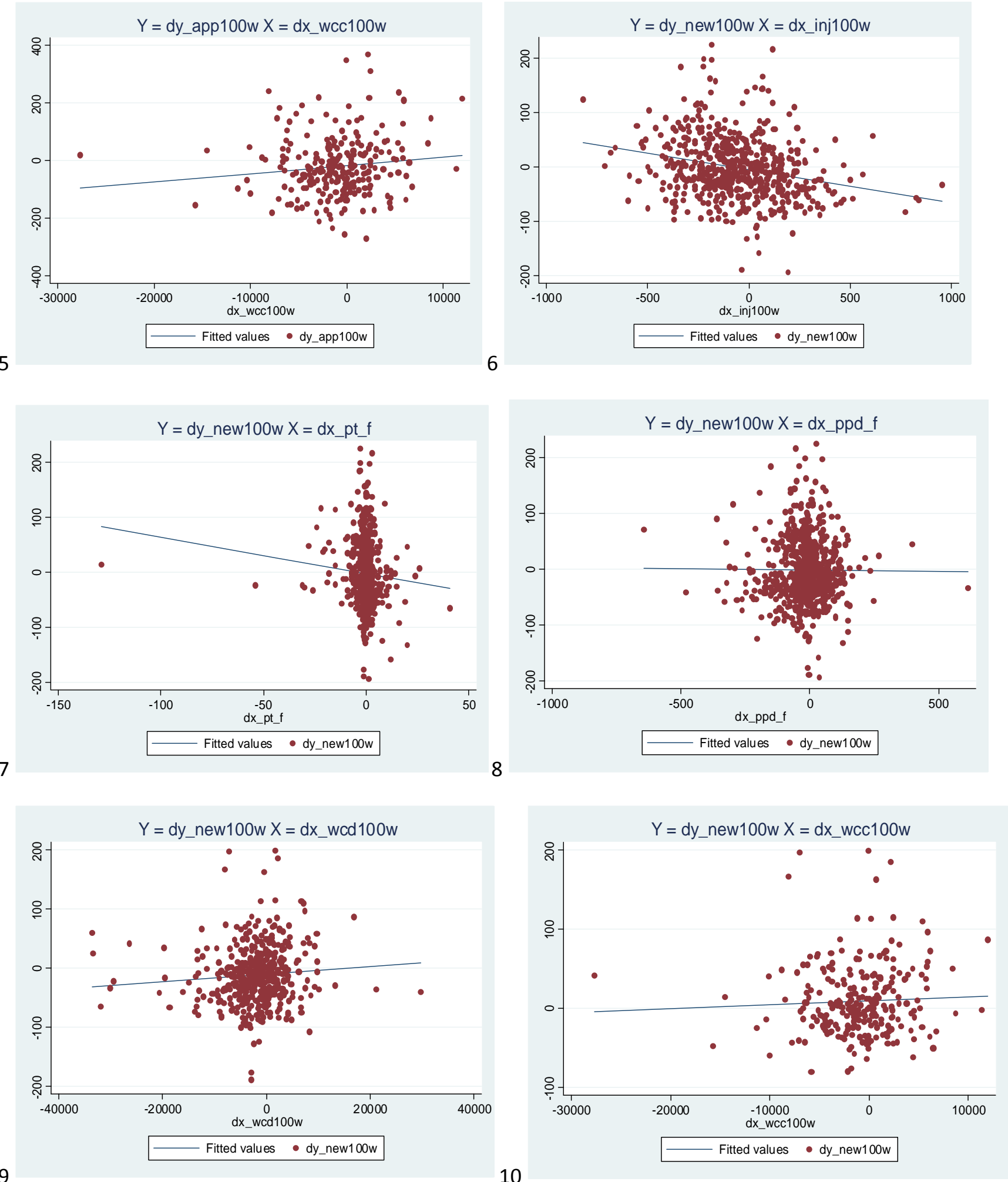

9

10 

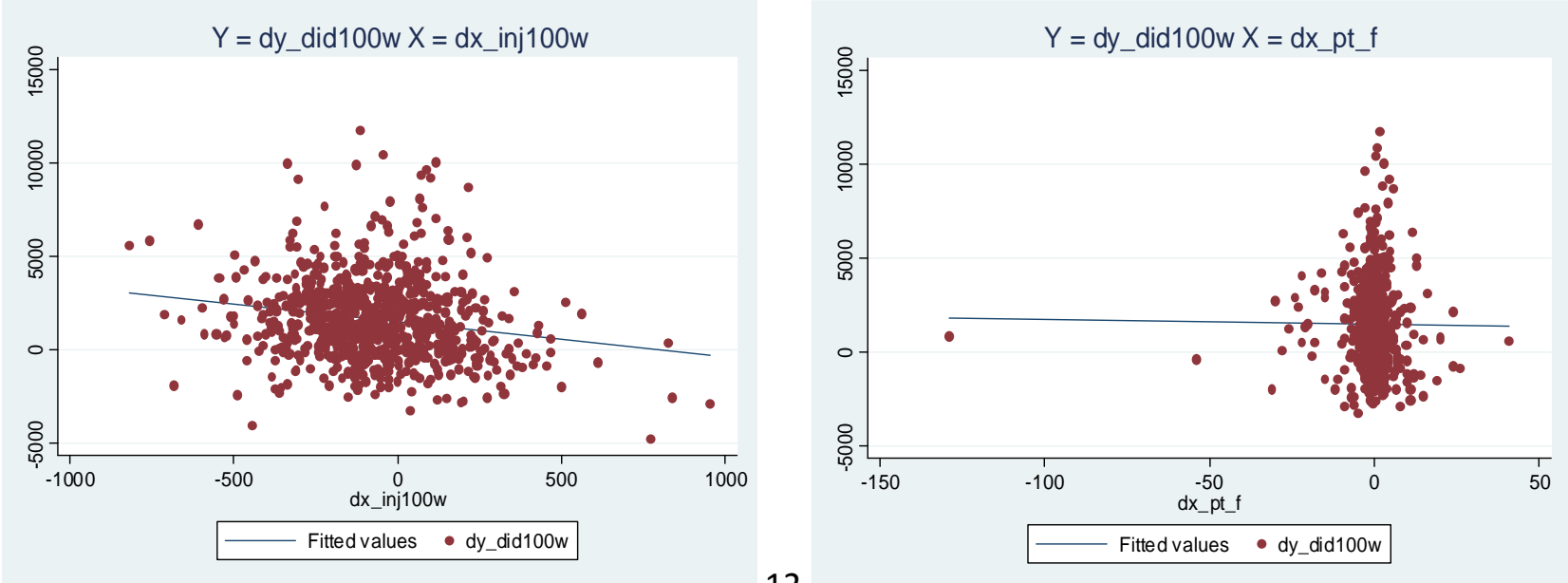

11

12
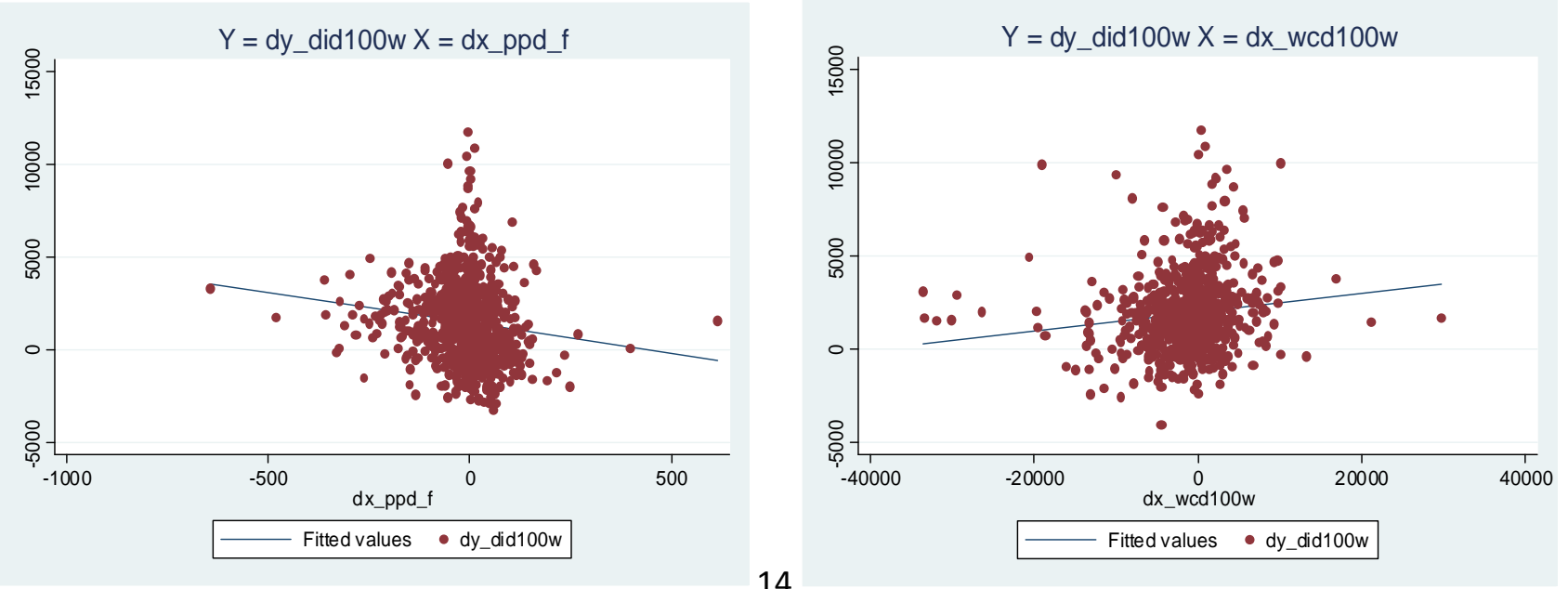

13

14

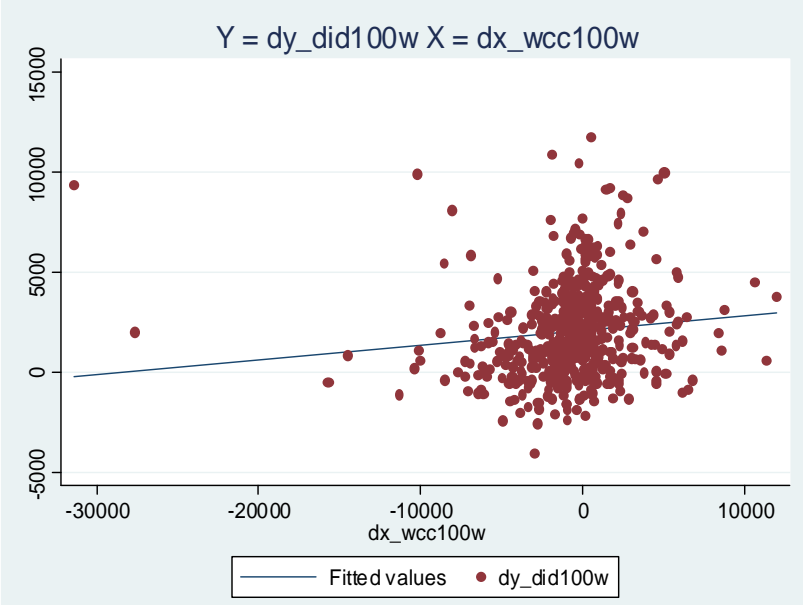

15 